\title{
20 Zusammenfassende Darstellung einiger exemplarischer Krankheitsverläufe
}

Aufgrund der Seltenheit kindlicher Schizophrenien und der auch damit zusammenhängenden diagnostischen Schwierigkeiten erscheint es sinnvoll, einige detaillierte Kasuistiken darzustellen, denen paradigmenhaft eine Art „Wiedererkennungswert“ eignen könnte. D.h., dass der Leser sich an eigene Patienten erinnert, die ein vergleichbares Symptombild zeigen. Dies könnte eine diagnostische Hilfestellung aber auch Anlass sein, mit dem Autor Kontakt aufzunehmen und einen Dialog zu beginnen. Ein weiterer Grund für die Notwendigkeit einer ausführlicheren Darstellung von Krankheitsverläufen ist die Tatsache, dass nur auf diese Weise die große Vielfalt und der Variationsreichtum früh beginnender Schizophrenien vermittelt werden kann.

\subsubsection{2b}

Nachbeobachtungszeit: 47 lahre

Familienanamnese

Der 4 Jahre ältere Bruder ist im Alter von 16 Jahren an einer rezidivierenden Schizophrenie erkrankt, deutliches Residuum. Er lebt allein, war verheiratet, geschieden, kein Kontakt zur Tochter. Lebt isoliert, typischer Eigenbrödler.

Ein 6 Jahre jüngerer Bruder litt an einer schweren rezidivierenden Schizophrenie, verstarb im Alter von 49 Jahren (unklare Viruserkrankung).

Zwei gesunde Geschwister.

Eine Schwester des Vaters (insgesamt 5 Geschwister) ist an Schizophrenie erkrankt (kurz nach ihrer Heirat im Alter von 24 Jahren), schweres Residuum.

Ein Bruder der Großmutter väterlicherseits sei eine Zeit lang „irrsinnig“ gewesen. 
Die Urgroßmutter väterlicherseits sei nach einer Entbindung „die Milch in den Kopf gestiegen".

Vorgeschichte: unauffällig

Prämorbid: lustig, ausgeglichen, mitfühlend, großer Freundinnenkreis, IQ: 100

Erkrankungsbeginn: 13 lahre, akut

\section{Psychopathologisches Bild}

Es traten zunächst 3-mal im Abstand von jeweils 28 Tagen depressive oder maniforme Verstimmungszustände auf, mit hypochondrischen Beschwerden, Traurigkeit, Schlaflosigkeit und Unruhe. Wenige Tage vor dem ersten Schub war das Mädchen „ganz aufgedreht und lustig“, tanzte herum und erzählte, es seien schon Drähte gezogen, es solle jetzt gefilmt werden, solle nach Amerika fahren, wo man es mit großer Pracht empfangen würde. Es war zeitweise ideenflüchtig und lachte häufig "so komisch“. In der Nacht vor der Klinikaufnahme schrie es plötzlich laut und gellend um Hilfe, war erregt, schlug um sich und schrie „Hilfe, ich muss ersticken“, „so eine Sau, so eine Sau“ und - zu den Eltern - „du bist der Teufel, du bist die Hexe“. Es habe "geträumt", dass ihm die Großmutter als Geist erschienen sei oder dass es ein Baby sei. In der Klinik war das Denken zerfahren, es äußerte zum Beispiel „sie sind alle mitgefahren, um die Familie zu heilen, schon die ganze Zeit, wie sie den Durchbruch gemacht haben, um mich zu führen, die Freche, die Judenstirne, steckt im Kopf, dass sie mich retten". Das Mädchen halluzinierte optisch und akustisch und entwickelte ein sehr vielgestaltiges und durch seine märchenhaft-phantastische Buntheit recht eindrucksvolles Wahngebilde: es sei die kleine Gisela, die „in der großen Gisela drin“ sei, es habe das Gefühl, dass es Strom abgäbe. „Wenn ich atme, wird es dunkel, es geht ein Strom von mir aus". Einmal sei es sich als in einem Ball eingewickelt vorgekommen, der Ball habe in einer Turnhalle gelegen, die angezündet worden und verbrannt sei. Der Ball sei aber nicht mitverbrannt, „weil ich da drin war und die Erde doch anzieht“. Es glaubte, „ein Nacktfrosch zu sein", dann wieder eine Olive, oder "das Sternkind, das Marienkind“, dann wieder die kleine und die große Gisela; es habe die Olive am Steuer gesehen und habe sie (die Olive) gelenkt. „Der Nacktfrosch, die Olive, ich bin schon ganz komisch davon. So ein bunter Wechsel von der Olive, dann wieder der Gisela, dann von der kleinen Gisela reden. Ich höre schon wieder schöne Musik im Ohr, in den Knochen merk' ich die Musik, ja das ist meine Stärke, die andere Kapelle muss spielen. Marienkindchen bin ich, freu mich nur wegen dem Licht, gucke immer so gern hinein, soviel Strom, die Fische und die ganzen Tiere. Hast du die gesehen. Ich bin das Marienkind“. Es habe von der Olive Lederjacken geschenkt bekommen. Es habe die Krätze, habe Blasen an den Fingern. Die ganze Familie sei krank. Das Mädchen äußerte weiterhin abnorme Körpergefühle: es tue ihm alles weh, es habe das Gefühl, als habe es einen Stein auf dem Bauch. Es spanne in den Armen und den Schultern, der Kopf sei so komisch wie ein Stein, sein Bauch sei „wie ein Sarg", „wie so ein Brett", „der Unterbauch sei dicker geworden“. Das Kind berichtete immer wieder über traumhafte Erlebnisse: „... als die Puppenstube mich irr gemacht hat, habe ich von der furchtbaren Judenstirne träumen müssen. "Das Mädchen litt unter starken Angstzuständen und sagte: „Ich kann doch nichts dafür, dass alles mir im Kopf rumgeht“. Nach 6 Wochen (Therapie: insgesamt 8-mal Elektroschock) distanzierte sich das Mädchen von seinen wahnhaften Gedankeninhalten. Der Gedankengang war klar und geordnet, das Kind hatte sein teils negativistisch-mutistisches, teils missmutig-trotzig-überhebliches Verhalten mit gereizter, flacher Affektlage und Antriebs- und Entschlusslosigkeit aufgegeben, zeigte aber noch eine ambivalente Gefühlshaltung seinen psychotischen Erlebnissen gegenüber. 


\section{Nachuntersuchung}

Die Patientin wurde überraschend aufgesucht, da sie mehrere Briefe unbeantwortet gelassen hatte. Sie war jedoch gern bereit zu berichten, und schnell war ein herzlicher, warmer Kontakt hergestellt. Die Patientin machte den Eindruck eines offenen, freundlichen, fröhlichen Menschen, wirkte vergnügt und ausgeglichen, dabei zugleich energisch, hausfraulich und tatkräftig (sehr großer Haushalt) und zeigte stark mütterliche Züge. Sie erinnerte sich noch an Einzelheiten ihrer Erkrankung, gab spontan an, dass sie damals Stimmen gehört habe, die ihr Befehle erteilten und die sie beschimpften. Seitdem sei sie nicht wieder erkrankt. Sie hat geheiratet, hat 3 gesunde Kinder. Die Ehe und das Verhältnis zu den Kindern seien gut. Die Wohnung war sauber und gepflegt, mit viel Blumen. Den Haushalt (großes Haus mit 2 Wohnungen) macht sie allein, putzt, bügelt, wäscht ohne Hilfe und versorgt ihre Kinder und ihren Mann bestens. Ihr Hobby ist Handarbeit, sie hat zahlreiche Freundinnen. Sie zeigte Sinn für Humor und schilderte sich als nicht nachtragend, sie könne sich aussprechen, rede sich ihr Anliegen von der Seele, sei optimistisch und lebe gerne.

\section{Epikrise}

Bei einer sehr starken familiären Belastung mit maligne verlaufenden schizophrenen Prozesspsychosen und schwersten postpsychotischen Residualzuständen ist die Patientin trotz frühen Erkrankungsbeginns bislang voll remittiert und 19 lahre nach Klinikentlassung erscheinungsfrei geblieben. Bemerkenswert ist das interessante und phantasiereiche Wahngebäude, welches das 13-jährige Mädchen in der akuten Psychose errichtet hatte.

\section{Nachuntersuchung}

28 Jahre nach der 1. Nachuntersuchung und 47 Jahre nach Erkrankungsbeginn fand die zweite persönliche Nachuntersuchung statt. Die inzwischen 60 Jahre alte Patientin erschien als eine sehr sympathische, warmherzig wirkende Dame. Sie hatte ein sehr hübsches Gesicht mit klaren blauen Augen. Sie war sehr gepflegt, stets freundlich und zugewandt. Sie kam relativ rasch auf ihre Brüder zu sprechen und auf ihre Mutter, die vor 2 Tagen hingefallen sei und sich die Hüfte gebrochen hätte. Nach dem Tod ihres ersten Mannes, der an einem Hirntumor verstarb, erkrankte die Patientin an einer langanhaltenden depressiven Phase mit Angstzuständen und vor allem mit dranghaften Selbstmordimpulsen. Sie habe nicht mehr leben wollen und immer wieder unter Impulsen gelitten, aus dem Fenster ihres Hauses zu springen und sich zu töten. Nur durch den Beistand ihrer Familie und vor allem auch der Vergegenwärtigung, dass sie ja ihre 3 Kinder zu versorgen hatte, habe sie sich mit aller Kraft dagegen gewehrt. Sie habe sich freiwillig in stationäre Behandlung begeben. Sie sei mit Antidepressiva und Benzodiazipinen behandelt worden. Die akute Phase habe etwa 4-6 Wochen angedauert, aber sie sei doch etwa $1 \frac{1}{2}$ lahre recht depressiv gewesen.

Weitere Schicksalsschläge: Tod des ersten Sohnes im Alter von 19 Jahren (Verkehrsunfall), Tod des zweiten Ehemannes (Lungensilikose). Die Patientin hat diesen Mann sehr aufopferungsvoll bis zum letzten Atemzug (Tod durch Ersticken) gepflegt. 4 Wochen vor der 2. Nachuntersuchung große Gefäßoperation der Bauchaorta und beider Beckenarterien.

Die Patientin arbeitet sehr gern und viel, sie habe viele Hobbys: Handarbeit, Garten, Blumen, Backen und Kochen. Sie versorge den Haushalt, den Garten und das große Haus selbst, ohne Hilfe. Sehr lebhaft und warmherzig spricht sie von ihren Enkeln, zu denen sie eine sehr gute Beziehung hat und die ihr auch einen großen Trost bedeuten. Die familiären Beziehungen sind eng, gut und herzlich, sie hat aber auch zwei ganz gute Freundinnen, die sie schon von Kindheit her kennt. Außerdem hat sie gute Bekannte, die sie besuchen. Sie erhalte fast täg- 
lich Besuch. Sie ist lebensfreudig, kontaktfreudig, gesellig, sie ist beliebt. Sie hat viele Telefonkontakte, sie schreibt viel. Ihr Lebensmotto heißt: „Ich muss mich nützlich machen“. Auch im Urlaub, wo sie gerne hinfährt, müsse sie etwas unternehmen, etwas tun und nicht faul herumsitzen. Sie lebe gerne trotz ihrer Schicksalsschläge, sie lasse sich nicht unterkriegen.

Die Patientin wirkt sehr realitätsnah, kann auch schwierige finanzielle Probleme lösen (Hausbau, Ausbau des Elternhauses, Vermietungen etc.). Sie ist lebenspraktisch und aktiv, ist gepflegt, hat Geschmack und Takt. Sie kann gut Entscheidungen fällen, ist durchsetzungsfähig und willensstark und trotzdem warmherzig, gutherzig, teilnahmefähig.

\section{Einstellung zur Krankheit}

Die Pat. erinnert sich sogar an Einzelheiten ihrer damaligen Erkrankung im Alter von 13 lahren. Sie erinnert sich spontan, dass sie Vater und Mutter als Hexe bzw. als Teufel bezeichnet hat. Sie sei damals „sehr aufgeregt“ gewesen. Sie bestätigt, dass sie damals Stimmen gehört habe und sagt: „Ich hab' auch drauf geantwortet“. „Ich hab' denen Märchen erzählt, die es gar nicht gibt". Spontan erinnert sie sich dann in diesem Zusammenhang, dass sie geschockt worden sei, sie sieht noch den Schockapparat vor sich, die Saugnäpfe, wie sie angelegt worden seien, „die elektrischen Dinger an die Schläfen gesetzt“. Sie habe auf einen Gummikeil beißen müssen. Das sei schrecklich gewesen. „Auch bin ich zu Gesprächen vorgeladen worden“.

Bewegend und bemerkenswert ist die Einstellung der Pat. zu ihrer damaligen Erkrankung: „Das ist nun mal gewesen“, sagt sie, als ich sie darauf anspreche, dass andere nicht gerne an die Erkrankung zurückdenken oder sehr beschämt sind und nicht gerne darüber sprechen wollen und schon gar nicht spontan von ihren damaligen psychotischen Symptomen sprechen. Sie fügt hinzu, „es ist ja auch in der Familie was“.

\section{Beurteilung}

6 Wochen anhaltende paranoid-halluzinatorische Psychose mit Denkzerfahrenheit, Coenästhopathien, Größenideen, akustischen und optischen Halluzinationen nach prodromartigem Beginn, (depressive und manische Prodrome). Ausgang in Vollremission trotz hochgradiger familiärer Belastung.

\subsubsection{4b}

Nachbeobachtungszeit: 45 Jahre

Familienanamnese: $0 . B$.

Milieu

Mittlere Mittelschicht (Beamtenfamilie, Vater Oberzugführer, eigenes Haus mit kleiner Landwirtschaft)

Psychomotorische Entwicklung: unauffällig

\section{Prämorbid}

Überempfindlich, Märchen hätten sie sehr „mitgenommen“. In der Schulzeit altklug, immer sehr genau, hat sich immer für die Einzelheiten interessiert, grüblerisch, aber auch fröhlich, feinfühlend. E. besuche die Volksschule, Hauptschulabschluss, guter Durchschnitt.

Erkrankungsalter: 13 lahre

Beginntyp: akut 


\section{Symptomatologie}

Plötzlich auftretende Angstzustände, das Mädchen weinte viel, bezog die Reden des Pfarrers auf sich, optische Halluzinationen (sah den Teufel). Das Mädchen sprach viel vom Himmel und von der Hölle und bezog Gesprochenes auf sich (Beziehungsideen). Gegen Ende dieser Phase (nach etwa 4 Wochen) schnippischer und lebhafter.

7 Wochen später zweite Episode (Dauer ebenfalls 4 Wochen). Das Mädchen sprach nur von Himmel, Hölle und vom lieben Gott, es litt unter Schlaflosigkeit, las viel in der Bibel.

Nach 7 Wochen das gleiche Bild.

Auch im Alter von 14 Jahren jeweils in siebenwöchigen Abständen auftretende Phasen mit Beziehungsideen und starken Angstzuständen, das Mädchen bezog alles auf sich. Während dieser Episoden war das Mädchen seiner Mutter gegenüber sehr abweisend und wollte „nichts von der Mutter wissen“.

Im Alter von $14 \frac{1}{2}$ |ahren erneut 4 Wochen lang andauernde Episode mit Angst, Schlaflosigkeit, ungewöhnlicher Willfährigkeit (tut alles prompt und ohne Widerstand, was man ihr sagt, „sie wird dann so zahm“" „die Augen verändern sich dann so, so einen trüben Blick“). Täglich sage das Mädchen: „Heute muss ich ganz bestimmt sterben“. Es schloss sich mit der Bibel ein: „Ich muss bereit sein für die Ewigkeit“. „Ich bin doch nicht verrückt“. Es äuBerte immer wieder die Angst, verrückt zu werden. Das Mädchen war weniger feinfühlend als früher, war sexuell enthemmt, geriet immer wieder in katatone Erregungszustände und litt unter wahnhaften Bedrohtheitserlebnissen, in denen es „wie eine Irre“ schrie, z.B. „das Feuer, das Feuer, es brennt, es brennt". Außerdem berichtete das Mädchen über imperative Stimmen („Ich muss tun was sie mir sagen“). Auf die Frage, wer ihr etwas sage, antwortete sie: „Ich weiß doch nicht, ich weiß doch nicht, aber ich muss doch tun, was man mir sagt“. Diese „Befehle“ bezögen sich auf etwas Religiöses.

Ein halbes Jahr später, im Alter von 15 Jahren, wurde die Patientin plötzlich unruhig, redete und betete viel, glaubte, der Vater wolle sie umbringen und geriet immer wieder in Erregungszustände, in denen sie u.a. rief: „ich habe mich aufgeregt, dass der Engel wieder singen würde, der Engel vom Himmel durch den erkannt wird, wenn ein Mord passiert ...". Das Denken war zerfahren. So antwortete das Mädchen auf die Frage, ob es sich nicht wohl fühle: „Bei Schlächtern nicht, der himmlische Vater sieht mehr vor Augen als ich. Ich bin schon im Haus zusammengebrochen und gehe ich so, dann sagt die eine so, dann schimpft die Elli so, durch Gottes Weisheit und Gnade .... „Ich bin verfolgt von den Menschen. Ich will sterben, ich war schon in Vergasung, aber mein Herz wollte nicht sterben. Sie schlachten die Mädels ab. Ich habe gehört von den Leuten. Erhaltungsunannehmlichkeit. Und mir fällt alles auf die Augen“. Das Mädchen gebrauchte Neologismen („Erhaltungsunannehmlichkeit“, „Ernstlichkeit“, „Apothekigkeit“). Es klagte über Gedankenjagen, Gedankenabreißen, Depersonalisationserlebnisse, äußerte immer wieder Verfolgungs-und Beziehungsideen und hatte akustische und optische Halluzinationen. Im übrigen war das Mädchen ausgesprochen sexuell enthemmt, küsste Jungen auf den Mund, masturbierte viel, war ohne Scham beim Entdeckt werden, reagierte darauf „inadäquat läppisch“. Ihre Bewegungen waren eckig, unkindlich, unbeholfen.

Therapie: 3 Elektroschocks.

Dauer der Episode: 12 Wochen. 
Entlassungsdiagnose: Hebephrene Schübe mit periodisch wiederkehrenden Beeinflussungsideen, Bedeutungserlebnissen, paranoiden Beziehungsideen, Angstzuständen, akustischen und optischen Halluzinationen, sexueller Enthemmung, manirierten Körperhaltungen, katatonen Erregungszuständen.

Leichte Defektzeichen (redet läppisch daher, emotional ohne tiefere Beeindruckbarkeit).

In der Folgezeit war das Mädchen völlig unauffällig, besuchte einen Tanzkurs, hatte viel Freude daran, war fröhlich.

Im Alter von $15 \frac{1}{2}$ Jahren traten wiederum Unruhezustände auf mit starkem Rededrang, das Mädchen betete plötzlich, geriet immer wieder in Tobsuchtsanfälle, äußerte Verfolgungsideen und glaubte, dass der Vater sie umbringen wolle. Wiederum war das Denken zerfahren: Sie spricht wieder vom Engel, durch den erkannt werde, „wenn ein Mord begangen wird“. Auf die Frage, wer ermordet werde, antwortete sie: „Niemand, verzeih, wenn ich verkehrt bin“. Sie sprach vom „Vergast werden durch Gott, zur Beerdigung in einen Menschen versinken. Ernstlichkeit hat er bestimmt nicht". Die Patientin litt unter starken Stimmungsschwankungen, vom Lachen ging sie plötzlich in gequältes Weinen über. Immer wieder kurz dauernde Erregungszustände, sie war dann nicht beeinflussbar. Sie äußerte Wahnideen, bei denen es um den Teufel, um Gott, um Ermordungen, um Engel geht. Weitere Symptome: Abnorme Körpergefühle, Inkohärenz und Zerfahrenheit des Denkens, Gedankenjagen, Gedankenabreißen, Neologismen, Depersonalisationserlebnisse. In der Folgezeit immer wieder katatone Erregungszustände mit Desorientiertheit.

Therapie: 9 Elektroschocks, 14 Insulinkomata.

Dauer der Episode: 3 Monate.

Nach Abklingen der psychotischen Episode erinnerte sich das Mädchen an seine psychotischen Zustände, konnte sie sich aber nicht erklären, es wisse nicht, wie das gekommen sei. Es habe immer noch etwas Angst, vor allem Angst, dass "alles wiederkommt“. Sie wolle dann „lieber sterben, anstatt verrückt zu werden."

\section{Weiterverlauf}

14 Monate erging es der Patientin gut. Im Alter von $16 \frac{1}{2}$ Jahren nach einem Kirmesbesuch kam es zu Schlafstörungen, Unruhe, Angstzuständen und Durcheinanderreden. Dieser Zustand war jedoch kurzdauernd und flüchtig.

Im Alter von 17 Jahren war eine erneute stationäre Aufnahme notwendig.

\section{Symptomatik}

Abnorme Körpersensationen, heftige Erregungszustände, hysterieforme Anfälle, die Patientin war unberechenbar und unbeeinflussbar, Inkohärenz des Denkens, Denkzerfahrenheit. U.a. beschuldigte sie ihren Vater, dass er wolle, dass sie verrückt werde. Sie habe ihn deshalb auf den Kopf geschlagen. Wörtlich sagte die Patientin: „Ich möchte nie verachtet werden. Ich wäre nie hergekommen, wenn der Unfall nicht gewesen wäre“. (Was für ein Unfall?) „Ich kann Ihnen das nicht sagen, stellen Sie das mal fest, prüfen Sie das mal. Ich kann mir nur vorstellen, dass die Tür aufging, meine Mutter sagte mir, dass sie das Essen abbestellt hätte, da kam eine Nachbarin und ich schlich als kleiner Engel durchs Fenster und das Unglück war passiert." (Warum sind Sie hier?) "Meine Schwester sagte, ich wäre schon viel früher krank gewesen und ich wollte nur nicht Wort halten. Ich merk' das, dann kommt irgendetwas über mich, ich merk 
das, so eiskalt, und dann denk ich nur, jetzt musst du in Sicherheit sein, dass du keine Gehirnerschütterung kriegst“. (Sind Sie freiwillig hier?) "Leider Gottes. Ich möchte gern gesund sein."

\section{Therapie}

12 Elektroschocks, danach leichte Besserung, die Patientin war ruhiger und lockerer, verhielt sich aber eigenartig und war immer wieder unruhig. Gelegentlich lag sie „verzückt mit verschlossenen Augen im Bett, still vor sich hin lächelnd“.

Dauer der Episode: 8 Wochen

\section{Weiterverlauf}

Im Alter von 19, 22, 25, 26 und 33 Jahren bis zu 12 Wochen lang anhaltende schizophrene Episoden mit ähnlicher Phänomenologie und ähnlichen Schweregrades, die unter stationärer Elektroschock- und Psychopharmakatherapie stets völlig remittierten.

\section{Nachuntersuchung der Patientin (Alter: 33 Jahre)}

Der Kontakt zur Patientin ist leicht herstellbar, sie ist freundlich, zugewandt, distanzlos, redselig, mitteilsam, dabei sprunghaft, ständig das Thema wechselnd, ständig von einem Gedanken ableitend, sie kann nicht bei der Sache bleiben. Ihre Stimmung ist heiter, freundlich, das Lächeln weicht nicht von ihrem Gesicht. Sie wirkt jedoch affektiv flach, ohne ansteckende Wärme. Die Freundlichkeit ist eher oberflächlich. Kein Anhalt für formale oder inhaltliche Denkstörungen. Keine produktiv-psychotischen Symptome.

Die Pat. gibt an, dass sie merke, wenn sie wieder auffällig werde. Sie müsse dann wieder in stat. Behandlung. Dabei möchte sie nicht gerne an ihre stat. Aufenthalte erinnert werden. Es beginne jeweils mit Schlaflosigkeit, Appetitmangel, Ekelgefühl vor dem Essen und darauf folgendem Gewichtsverlust. Sie werde dann misstrauisch, ratlos, habe Angst, sei voll innerer Unruhe, fühle sich innerlich erregt und schwach. Sie wolle dann nicht allein sein, leide unter Vereinsamungsgefühlen, habe das Gefühl der Verlassenheit, sei dann traurig und grüble viel. Sie sei in diesen Zeiten vergesslich und reizbar. Sie sage in diesen Zeiten „frei weg, was man nicht sagen darf“. Der Vater der Pat. gibt an, sie sei in diesen Zeiten besonders aggressiv. Die Belastungsfähigkeit nehme dann ab, ihr werde alles zu viel. Sie ziehe sich zurück und meine, die Leute sehen ihr dann an, dass sie krank sei. Es komme ihr alles so unwirklich, so fremd vor. Wenn sie krank sei, sei sie „am liebsten tot". Allerdings habe sie nie die Absicht gehabt, sich umzubringen, „das tut ja weh“. Während der Krankheitsphase habe sie keinen Antrieb, keinen Schwung, zu nichts Lust.

Die Patientin berichtet, dass sie sich leicht aufrege, reizbar sei, sonst sei sie zufrieden und schätzt sich als hilfsbereit ein. Es ist jedoch eine deutliche affektive Nivellierung zu beobachten, die Patientin spricht ohne spürbare innere Anteilnahme. Im Gedankengang ist sie sprunghaft, sie spricht ohne Zusammenhang über ihre Krankheit, dann von irgendeinem Dorf-Klatsch, fragt mich, ob ich Stationsarzt werden wolle, ob in M. noch geschockt würde, sie würde lieber Medikamente nehmen. Sich selbst und ihren Fähigkeiten gegenüber ist sie völlig kritiklos. Das Verhältnis zur Familie sei gut. Auch zu ihrer Umgebung bekommt sie schnell aber nur oberflächlichen Kontakt. Sie ist gutgläubig, vertraut anderen leicht, sei vertrauensselig, distanzlos, kritiklos, gutartig.

Zweimal sei sie verlobt gewesen, die Verlobungen seien jedoch bald wieder gelöst worden, sie sei „gut darüber weggekommen“. 
Einen Beruf kann sie nicht ausüben, sie hat versucht als Serviererin zu arbeiten, war jedoch rasch überfordert, sie brauche Ruhe. Zu Hause sei sie fleißig, beschäftige sich mit einfachen Arbeiten im Haushalt wie Putzen, Staubwischen, Geschirrspülen. Ihre Lieblingsbeschäftigung sei Sticken.

Ihre Zukunftspläne: „Alles schön in Ordnung machen, Bungalow bauen, nie wieder krank werden, das große Los ziehen, das wäre mein Zukunftsplan und heiraten". Die Patientin bringt dies alles recht unzusammenhängend vor, wirkt dabei kindlich und unernst.

Bei einer Intelligenzprüfung nach Kloos (1958) (Unterschiedsfragen, Begriffsbestimmung, Oberbegriffe bilden, Sprichwörter deuten, Sinnwidrigkeiten erkennen, Bilder deuten) zeigt die Patientin deutliche Einschränkungen. Ihr Denken ist konkretistisch, das Wesentliche wird nicht erfasst, sie neigt stattdessen zu Floskelbildungen und Abschweifungen. So antwortet sie auf die Frage nach dem Unterschied zwischen einer Treppe und einer Leiter: „Was soll ich da sagen, kann auch nicht so sagen, weiß nicht ... gar keine ... bei der Treppe fällt man leicht runter". Auf die Frage nach dem Unterschied zwischen Glaube und Wissen antwortet sie: „Das ist so kompliziert, diese Frage, weiß ich nicht, wahrhaftig nicht“ und schließlich: "Glaube, wenn man was glaubt, Wissen, wenn man viel weiß“. Auf die Frage, ob sie sagen könne, was eine Insel sei, antwortet sie „Ich weiß was es ist, kann es aber nicht sagen“.

Beim Bilderdeuten sagt sie zum Bild „Blinde Kuh“: „Der zieht die Decke weg, weil er wegläuft". Die Patientin war weder in der Lage, geläufige Sprichwörter zu erklären oder Sinnzusammenhänge (Bilderdeuten, kurze Fabeln) zu erkennen und Sinnwidrigkeiten zu durchschauen. Die Nachuntersuchung ergab deutliche Zeichen einer affektiven Nivellierung, die früher empfindsame und feinfühlende Patientin erschien jetzt als emotional flach, kindhaftunbekümmert, kritik- und distanzlos. Deutliche kognitive Einbußen.

\section{Weiterverlauf}

In den Folgejahren war die Patientin weitgehend beschwerdefrei, sie lebte im Haushalt der Schwester und hat deren Kinder versorgt sowie die gemeinsame Mutter betreut. In dieser Zeit ging es ihr recht gut, sie war stabil. Nach Lösung einer Verlobung im Alter von 40 Jahren kam es zu vermehrter Unruhe, zu Schlafstörungen, vermehrter Reizbarkeit und Beziehungsideen. Die Krise ging spontan wieder vorbei. Seitdem Behandlung mit Neuroleptika (Taxilan und Truxal).

Im Alter von 60 Jahren war wegen einer vorwiegend depressiven Symptomatik ein 5 Monate langer stationärer Aufenthalt notwendig (Unruhe, Antriebsminderung, gedrückte Stimmung, Appetit- und Schlafstörungen).

\section{Nachuntersuchung, 45 Jahre nach Erkrankungsbeginn, Alter der Patientin 62 Jahre}

Zunächst werden Schwester und Schwager exploriert. Sie berichten, dass der psychopathologische Zustand seit Jahren relativ konstant sei. Die Patientin sei misstrauisch, übelnehmend, leicht eingeschnappt, zänkisch, glaube, dass die Leute über sie reden. Wenn die Schwester zur Nachbarin gehe, müsse sie gleich hinterher rennen, weil sie glaube, dass die Schwester und die Nachbarin über sie schlecht reden. Keine Verfolgungsideen. Deutliche Minderwertigkeitsideen. Patientin traut sich nichts zu. Sie sei passiver und inaktiver als bei der letzten Nachuntersuchung vor 29 Jahren. Die Patientin lege Wert auf Körperhygiene und gute Kleidung. Sie helfe wenig im Haushalt, nur bei der Wäsche, sie bügele gerne. Sie bereite allenfalls einfache Speisen zu, erledige das Tischdecken. Insgesamt sei sie nicht mehr so ordnungsliebend wie früher. Man müsse sie zu allem auffordern. 
Die Patientin habe kaum Hobbys, beschäftige sich wenig. Sie lese Zeitung, höre Radio, sehe fern, interessiere sich für die täglichen Nachrichten, verfolge politische Sendungen, eine vertiefte politische Diskussion sei jedoch unmöglich. Sie wisse aber in Grundzügen, was in der Welt passiere. Sie sei keineswegs abgestumpft oder dumm. Sie mache sich Sorgen um ihre Rente und bekomme mit, dass auch durch die Privatisierung der Bahn möglicherweise ihre Rente gefährdet ist. (Der Vater war Oberzugführer).

In letzter Zeit ziehe sie sich gern von ihren Bekannten zurück, sie sei leicht beleidigt, fühle sich leicht zurückgesetzt, sei missgünstig, könne die Wahrheit nicht vertragen, erhebe auch unberechtigte Vorwürfe gegenüber dem Schwager, behaupte, dass er kein Geld in die Ehe gebracht habe. Sie verstehe Scherze leicht falsch, bekomme sie in den falschen Hals, sie sei überhaupt leicht beleidigt, beziehe alles auf sich. Sie missdeute Zuwendung, z.B. Lächeln als Auslachen, werde dann heftig, drohe der Schwester Schläge an oder schlage sie auch. Andererseits necke sie gerne und "stichelt“. Im Übrigen sei sie sehr schlagfertig, schnippisch, der Schalk sitze ihr im Nacken. Starkes Mittelpunktstreben, sie könne nicht zuhören, telefoniere sehr gerne, vor allem mit dem Bruder und der Schwägerin. Die Stimmung sei wetterabhängig. Morgens sei sie eher „gut drauf“, mittags wäre sie sehr reizbar, empfindsam und zänkisch. Abends im Bett mache sie sich viele Gedanken, Selbstvorwürfe, am nächsten Tage entschuldige sie sich dann für ihre Frechheiten. Sie sei sehr empfindsam.

\section{Exploration der Patientin selbst}

Sie berichtet, sie sei leicht aufgeregt, sie meint, ihre Mutter habe sie nicht gerne gehabt und begründet dies damit, dass sie durch Schuld der Mutter im Alter von 21/2 lahren als Kleinkind eine Verbrennung durch heiße Milch erlitten habe.

Ihre Einschätzung zu sich selbst und zu ihrem Leben ist sehr unkritisch, sie sei mit ihrem Leben recht zufrieden, fühle sich nicht eingeschränkt, sie arbeite gerne, schaue gerne fern. Manchmal sei sie auch unzufrieden, „, weil ich krank bin“.

Die Patientin redet viel, ist logorrhoeisch, kommt „vom Hölzchen aufs Stöckchen“, der Zusammenhang ist äußerst locker, ihr Denken und Sprechen inkohärent. Immer wieder äußert sie Beziehungs- und Beeinträchtigungsideen.

Bei der Intelligenzuntersuchung gibt sie fast identische Antworten wie 29 Jahre zuvor bei der ersten Nachuntersuchung.

\section{Medikation}

$150 \mathrm{mg}$ Clozapin täglich. Die Medikamenteneinnahme muss überwacht werden.

\section{Zusammenfassung}

Deutliche postpsychotische Persönlichkeitsveränderung. Verminderte emotionale Reagibilität, mangelnde emotionale Tiefe, ausgeprägte paranoide Tendenzen, Antriebsarmut, Mangel an überschauendem Denken, Neigung zu konkretistischem Denken, Einbuße an Affektivität und Zielgerichtetheit sowohl im Denken als auch im Handeln, Neigung zu gedanklichen Stereotypien, lockerer bis logorrhoeischer Gedankengang. Andererseits auch zeitweise rasches Erfassen der Situation mit schlagfertigen Reaktionen. Neigung zu starker Reizbarkeit und mehr oder weniger starker Aggressivität, ausgeprägte Empfindsamkeit. - DAS-M-3: 4 (schlechte soziale Remission). 


\subsubsection{5 a}

Nachbeobachtungszeit: 42 Jahre

\section{Familienanamnese}

V. ist das jüngste von 11 Kindern.

Ein Bruder erkrankte im Alter von 17 Jahren an einer rezidivierenden paranoid-halluzinatorischen Schizophrenie.

Die älteste Schwester zeigt auffallende paranoide Züge und maniforme Symptome (Inkohärenz des Denkens, inadäquater Affekt).

Der jüngste Bruder suizidierte sich im Alter von 21 Jahren (Strangulation).

Eine Schwester des Vaters leidet an einer Pfropf-Schizophrenie bei geistiger Behinderung und wird seit 42 Jahren stat. behandelt.

Ein Bruder des Vaters litt an einer progressiven Paralyse. Der Vater hatte insgesamt $3 \mathrm{Ge}$ schwister.

Zwei Urgroßväter väterlicherseits (Großväter des Vaters) sind in Anstalten verstorben.

Der Vater der Mutter der Patientin litt an einer rezidivierenden Schizophrenie.

Der Vater war von Beruf „Hilfsmaurer“, arbeitsscheuer Sonderling, sehr hart, misshandelnd.

Mutter: Psychisch unauffällig. Tochter eines Trinkers (Beruf: Fischer).

Milieu: Sehr einfache Verhältnisse. Vater sehr launisch, misshandelnd, immer sehr laut. Die Schwester von V. schreibt in einem Brief: „Hätte er (der Vater) nicht seine dummen Späße an V. ausgelassen, sie wäre gewiss normal“. „Man konnte V. nicht vor ihm schützen, meine Mutter war schwach, sie sagte immer nur ach', lass sie doch allein“!

\section{Psychomotorische Entwicklung: keine Auffälligkeiten}

\section{Prämorbid}

Mäßig intelligent, einmal sitzengeblieben, zänkisch, etwas wild, einzelgängerisch, kontaktschwach, willfährig, ich-schwach

Beginn: plötzlich,

\section{Erkrankungsalter: $7 \frac{1}{2}$ Jahre}

\section{Psychopathologisches Bild}

Ohne äußeren Ansatz setzte im Alter von 7 Jahren bei dem Mädchen eine auffallende Wesensänderung mit akuten Verhaltensauffälligkeiten ein: Das Kind lachte völlig unmotiviert, schrie häufig völlig situationsinadäquat, redete verworren („richtiges Chinesisch“). Es identifizierte sich stundenlang vor dem Spiegel stehend mit einer Spielkameradin. Es personifizierte Dinge und behauptete beim Anblick eines Zuges „der niest und hustet ja“. Das Mädchen wurde zunehmend scheu, ängstlich abwehrend, verkroch sich vor Fremden, reagierte auf Fragen der Angehörigen mit abwehrenden Handbewegungen, hatte Angst vor der Toilette. Seine WCFurcht begründete es mit den Worten: „Da sitzt einer drin, der zieht mich runter in den Pfuhl“ (s.a. Kap 17!). Das Mädchen machte sein Geschäft in den Kleiderschrank seiner Schwester und unter das Kopfkissen der Schwester. Überall sah es Augen, die es beobachteten („ei, die 
gucken mich alle so frech an mit ihren ekelhaften Augen, so große Augen haben die alle"). Deshalb habe es alle Bilder und den Spiegel umgedreht. Früher recht tierlieb fing es an, die Hauskatze zu quälen und schrie: „Ich kratze dir die Augen aus, du guckst mich so frech an“.

Emotional wurde das Mädchen als völlig abgestumpft beschrieben, es habe keinerlei Gefühlsregungen mehr gezeigt, weder Liebe noch Anhänglichkeit. Es gebrauchte „ganz abscheuliche Schimpfworte" und machte alles kaputt, aß unmäßig viel, alles was es fand, Blätter, Blumen, Abfälle aus Eimern und Papierkörben, Zigarettenstummel etc. Gegen Strafen war es völlig unempfindlich, lachte nur "seltsam und verdrehte die Augen“. Mehrmals lief es von zu Hause weg und versuchte sich vor den Zug zu werfen.

In der Sonderschule stand das Mädchen plötzlich mitten im Unterricht auf, pfiff, quälte und ärgerte andere Kinder, störte durch ständiges Dazwischenreden. V. schimpfte viel unmotiviert vor sich hin, z.B. „alte dreckige Sau, ich bring dich um, ich erwürg' dich, wart' nur ..."

Im Alter von 8 Jahren stationäre Aufnahme (Psychiatr. Univ. Klinik Heidelberg). Das Kind war voller Angst, versteckte sich sofort unter den Betten, berichtete spontan über akustische und haptische Halluzinationen. Es habe eine Schlange im Bauch und im Kopf. Das Essen sei vergiftet, alles rieche nach Gift. Das Mädchen lauschte, hielt sich die Ohren zu, grimassierte, schimpfte in den übelsten Ausdrücken. Jegliche Berührung wurde ängstlich abgewehrt durch Treten, Stoßen, Kneifen. V. hörte Stimmen: „|a, die Menschen in meinem Kopp, die reden immer was", „du Krabbe, du Drecksau, lauter hässliche Worte sagen die mir“, die Stimmen würden ihr befehlen, die Schimpfworte zu wiederholen und Fragen nicht zu beantworten. Das Kind äußerte: „Ich hab' so Bauchweh, ganz schrecklich ist das, da ist eine Schlang' drin, ich bin vergiftet .... . V. fühlte sich von bösen Mächten verfolgt und äußerte immer wieder Vergiftungsideen. V. verweigerte die Nahrung, sie grimassierte heftig und geriet immer wieder in katatone Erregungszustände und berichtete weiterhin über transitivistische Depersonalisationserlebnisse, sie identifizierte sich mit Personen der Umgebung, war sehr unsauber, kotete ins Zimmer, war sexuell enthemmt und neigte immer wieder zu sinnlosen Impulshandlungen mit Zerstörungsdrang. Sie war autistisch zurückgezogen.

Intelligenzuntersuchung: knapp durchschnittliche Intelligenz

Während der stat. Behandlung wurde das Mädchen mit Elektroschocks und Megaphen behandelt.

Immer wieder kam es zu kataton-stuporösen Erregungszuständen, das Kind war sexuell völlig enthemmt und autistisch. Teilweise war das Verhalten läppisch, maniriert. Das Mädchen halluzinierte heftig. Zu einer alten Patientin sagte es: „Ich möchte dir die Pupillen herausreißen“, es musste gewaltsam aus deren Nähe entfernt werden. Bei jedem Essen äußerte es Vergiftungsideen und untersuchte den Inhalt des Essens. V. verhielt sich meistens sehr trotzig, lehnte sich gegen alle Vorschriften auf, war unsauber, nässte ein, stand unter dem Einfluss akustischer Halluzinationen. V. hielt sich dann beide Ohren zu, machte ein gequältes Gesicht und berichtete von "fürchterlichen Qualen“, die sie aushalten müsse. Schlangen würden ihren Magen zerfressen. Manchmal war sie vergnügt, lachte plötzlich auf, aß maßlos alles in sich hinein, auch Abfälle.

Nach 7 Monaten wurde V. versuchsweise nach Hause entlassen. 7 Monate später wurde das inzwischen 81/4 Jahre alte Mädchen in der Univ. Klinik Marburg aufgenommen. Dort war es ängstlich, mutistisch, abweisend, hatte keinen Kontakt zu Mitpatienten und Schwestern, sprach nicht, war negativistisch, mutistisch, kataton-stuporös, kotete ins Zimmer. Es hatte halluzinatorische Erlebnisse, sah plötzlich ein Kalb auf sich zukommen. Es masturbierte ohne 
Scham vor Fremden und hörte nach wie vor "Stimmen im Kopp“. Es äußerte auch immer wieder Vergiftungsideen.

Eine Behandlung mit 25 ES blieb ohne wesentlichen Erfolg. Das Mädchen sprach aber jetzt im „Telegrammstil“. Danach Beginn einer Megaphen-Behandlung. Auch darunter immer wieder sinnlose Impulshandlungen.

Nach einem halben Jahr Verlegung in ein süddeutsches PLK. Es bestand ein ausgeprägter schizophrener Defektzustand. Das Mädchen war autistisch, kontakteingeschränkt, distanzlos, enthemmt, häufig aggressiv. Ganz erhebliche Angstzustände, Fressgier, sexuell triebhaft-enthemmt. Das Mädchen warf das Essen über den Tisch, spuckte den anderen in die Teller, erledigte ihr großes Geschäft auf der Straße. Mangelhafte Körperpflege, ab und zu akustische Halluzinationen in Form von Stimmen.

\section{Symptombild im Alter von $9 \frac{1}{2}$ Jahren}

V. stand nach wie vor unter dem Eindruck von akustischen und optischen Halluzinationen, starrte immer wieder in eine Ecke und murmelte vor sich hin, schreckte dann plötzlich zusammen, schrie ohne erkennbaren Grund laut auf. Das Mädchen nahm nicht an gemeinsamen Aktivitäten teil und hatte keinen Kontakt mit anderen Kindern.

Encephalographie: Linker Ventrikel etwas weiter als der rechte, sonst o.B.

Im Alter von 10 Jahren war das Kind ausgeglichener und ruhiger, spielte mit Puppen, war nicht mehr triebhaft enthemmt, war sehr viel besser im Kontakt, war ganz verändert gegenüber früher, „nicht wiederzuerkennen“. V. machte eifrig im Schulunterricht und beim Basteln mit, kein Anhalt für psychotische Symptome. Damalige Beurteilung: „Wenn man sie nicht von früher her kennen würde, würde man wohl nie vermuten, dass sie eine Schizophrenie durchgemacht hat".

Die Besserung hielt insgesamt $2 \frac{1}{2}$ Jahre an. Im Alter von 12 Jahren traten jedoch wieder psychotische Symptome auf. V. wurde unsauber und enthemmt, urinierte auf den Boden ihres Zimmers, kotete ins Zimmer, war völlig autistisch, beantwortete selten Fragen, stellte selber aber viele kleinkindliche Fragen und hörte wieder Stimmen, die ihr Befehle erteilten. Ihr Verhalten wechselte zwischen Kontaktarmut und trotzig-negativistischem, albern-läppischem Verhalten. Sie war antriebsarm, drückte sich vor jeder Arbeit und zeigte wenig Schamgefühl.

\section{Therapie}

Verschiedene Neuroleptika (Lyogen, Phasein, Truxal, Megaphen).

Die Pat. geriet immer wieder in schwerste Erregungszustände und war sexuell stark enthemmt. Unter dem Einfluss imperativer akustischer Halluzinationen zerriss das Mädchen immer wieder Kleidung und Wäsche. Es erschien völlig autistisch, ohne sichtbare affektive Gemütsäußerungen und war völlig antriebsverarmt.

Dieser Zustand, unterbrochen von länger anhaltenden psychotischen Phasen mit vorwiegend kataton-halluzinatorischer Symptomatik, hält nun insgesamt 37 lahre an! Immer wieder gerät die Patientin in schwere Erregungszustände, schreit laut auf, voller Angst, schreit, „dass der Hedemichel kommt", vor dem sie sich fürchtet und der ihr befiehlt, Kleider und ihr Bettzeug zu zerreißen. Sie fühlt sich von dem Hedemichel verfolgt und geängstigt, er erteile ihr „Befehle". Ihr Verhalten wechselt zwischen freundlichem, ruhigem und verträglichem Benehmen und katatonen Erregungszuständen, in denen sie Bettwäsche und Kleidung zerreißt, unfreundlich und mürrisch ist. Immer wieder kommt es zu unmotivierten Aggressionsdurch- 
brüchen, in denen sie Mitpatienten anfällt, sie kratzt und beißt. Auch hat sie gelegentlich Suizidimpulse, die Fenster müssen geschlossen werden, sie müsse sich sonst hinabstürzen. Gelegentlich auch optische und coenästhetische Halluzinationen. Zwischendurch nimmt sie an einer BT (2 Std./Woche) teil, der Antrieb ist jedoch sehr herabgesetzt, eine sinnvolle Beschäftigung ist außerhalb der BT nicht möglich. Immer wieder sitzt sie in einer Ecke, lacht laut und hört ihren Stimmern zu.

\section{Nachuntersuchung im Alter von 491/2 Jahren, 42 Jahre nach Erkrankungsbeginn}

V. hat ihr Kindergesicht behalten, sie trägt praktisch die gleiche Frisur und hat ausgesprochen kindliche Gesichtszüge. Man kann sich V. gut als 7/8-ähriges Kind vorstellen. Allerdings sind die Gesichtszüge doch deutlich vergröbert und von der langen Krankheit gezeichnet.

V. bekommt von mir einen Apfel und befiehlt dann: „Schneid” mir den Apfel“. Sie leckt an der Tasse immer wieder, obwohl nichts mehr drin ist. Sie nimmt nur kurzfristig Kontakt auf. Man kommt aber doch schließlich in ein Gespräch mit ihr. Sie behauptet, dass ihre „Mama“ sie besuche. (Frage: Wie alt ist Ihre Mama?) Antwort: „Älter wie ich“. Sie habe eine Puppe "Gertrud“. Das sei „ihr Kind“. „Meine Puppe hab' ich auch Gertrud getauft“. Auf meine Frage meint sie, dass sie die jüngste von den Kindern sei, sie sei „30 lahre alt“. - Gertrud ist ihre ältere Schwester, die in Amerika lebt. Ihre Lieblingspuppe sei die Gertrud. (Wo die denn wohne?) Antwort: „In Worms“. (Frage: Wohnt sie nicht in Amerika?) Antwort: „|a“.

(Frage: Warum sind Sie hier?) „Warum bin ich hier?“, „Warum bin ich jetzt hier“? Sie wiederholt diese Frage zweimal. Auf meine Frage, ob sie gern hier sei: „|a, hier gefällt's mir gut". Sie meint, dass ihr die Bilder hier an den Wänden gefallen würden. (Sie haben auch Bilder gemalt?) V. wiederholt mehrmals heftig "nein, ich hab keine Bilder“. Sie neigt zu stereotypen Satzwiederholungen. Schließlich stellt sie fest: „Heute Mittag gab's Suppe und weiße Würschte, die haben geschmeckt“. Auch diesen Satz wiederholt sie immer wieder.

\section{Beschäftigungen}

Sie gehe spazieren, pflücke Blumen, mache kleine Einkäufe, etwa im Wert von 2,- DM bis 3,- DM, sie achte aber nicht auf das Wechselgeld. Sie zählt hier aber richtig ihr Geld, 80 Pfennig hat sie bei sich. Sie ist sehr ordentlich, sie wäscht und duscht sich, letzteres sogar sehr gerne, zweimal täglich. Sie macht die Betten, auch für die Mitpatienten. Sie fegt die Räume und ordnet alles. Die Stühle werden richtig hingestellt etc.

\section{Zeitlich ist sie nicht orientiert}

Sie meint, es wäre „Dezember", sie gibt auch den falschen Wochentag an und kann sich erst durch mechanisches Aufzählen an den richtigen Wochentag heranrobben. Sie meint, es sei Dezember es ist aber Sommer. Schlaf und Appetit seien gut. Sie schlafe mit ihren Puppen, die sie mechanisch an- und auszieht und die in ihrem Bett viel Platz einnehmen. Sie möchte gerne rote Hausschuhe haben, weiße und schwarze Strümpfe und eine rote Lackhandtasche.

Erregungszustände wie früher sind seit 2-3 lahren nicht mehr aufgetreten. Selten reißt sie noch Knöpfe ab.

(Frage: Erinnern Sie sich als Sie noch Kind waren?) Antwort: „Da bin ich im Kinderwagen gelegen“. (Wer hat den geschoben?) „Meine Schwester“. (Gertrud?) „,a“. Ich frage sie, ob sie sich daran erinnere, dass sie mal eine Schlange im Bauch gehabt habe. Darauf fragt sie zurück: „A Schlang im Bauch? Das weiß ich net mehr“. (Menschen im Kopp?) Antwort: „|a, im Kopp“, sie nickt dabei. Ich frage nach dem „Hedemichel“. Sie sagt: „Der Hedemichel, 
der kommt nimmer“. (War das ein freundlicher Kerl?) „Freundlich“. (Was hat der gesagt?) „Ich soll die Kleider kaputt mache“. (Sind sie froh oder traurig, dass er nicht mehr kommt?) Antwort: „Ich bin froh, dass der net mehr kommt“. Und sie fährt unmittelbar fort: „Morgen fahren wir fort, alle kommen mit“. Der „Hedemichel“ kommt zwar nicht mehr, aber der „Kurt“ kommt: „Der geht mit mir ins Gebüsch“. (Was macht der da?) Antwort: „Poussieren“. „Das macht mer net, das macht mer net, Geld gebe hat er mir net, der hat mer Geld gebe, jetzt gibt er mir keins mehr".

V. berichtet über optische Halluzinationen: plötzlich lacht sie und sagt: „Ei, der Kurt ist wieder da, da steht er doch“. (Wie alt ist er?) Antwort: „Wie alt könnt’ der denn sei?“ Er sei 40. Er sei größer als ich und plötzlich sagt sie: „,a, da war'ne Schlang' im Bauch, die ist jetzt fort". (Was hat die gemacht?) „Die wollt' mich beiße, da hab' ich Angst gehabt vor der Schlang')." Noch einmal gefragt, wie es früher war bei ihrer Erkrankung, sagt sie: „Wie ich 'ne Schlang' im Bauch gehabt hab“.

Von der betreuenden Krankenschwester ist zu erfahren, V. sei leicht beeinflussbar, sie sei gut lenkbar, sei nicht mehr aggressiv, bis auf wenige Ausnahmen. Sie schimpfe gelegentlich vor sich hin. Früher habe sie andere Leute in den Nacken gebissen. Plötzlich sagt V: „Was bedeutet Honolulu? - Die Hauptstadt von China“. (Frage: Welches ist die Hauptstadt von Deutschland?) „Weißenau“. V. neigt zu Echolalie, zu stereotypen Wiederholungen von Sätzen und Satzbruchstücken.

Sie berichtet, Stimmen in ihrem Kopf hätten ihr gesagt, sie solle die Knöpfe abreißen, das seien Männerstimmen gewesen, gibt sie auf Nachfrage an. Es gebe auch ",andere Stimmen“, die hätten ihr gesagt: „Ich soll lieb sein“.

Plötzlich lacht sie und sagt, „der Kurt ist mit mir gegange“, er sei lieb zu ihr. - „Kurt“ ist ein seit einigen Jahren verstorbener Patient. - Unmittelbar fährt sie fort: „Die Vera sagt, ich bin auch dreißig“. (Frage: Ist die auch in dir drin?) V. nickt. (Frage: Die Vera ist in dir drin?) Antwort: „|a“. „Die Vera, die sagt mir, es gibt auch 'ne schwarze Milch“. Die schwarze Milch sei von den schwarzen Kühen. Plötzlich singt Vera: „Drum schlag dir Frankfurt aus dem Sinn, und wende mich weiß Gott wohin, ich will mein Glück probieren, marschieren, marschieren“.

\section{Aktuelle Medikation}

$400 \mathrm{mg}$ Neurocil und $400 \mathrm{mg}$ Atosil tgl., alle 4 Wochen 3ml Haldoldecanoat.

Beim Betrachten der Bildertafeln von Kloos sagt sie zum „Blindekuh“-Bild: „A Mann und a Mädche, die spiele“. (Was spielen die?) „Die spielen Versteck. Und die sucht jemand“. (Blind?) „Blindekuh“.

Zum Schneeballbild sagt sie: „Der nimmt den an dem Haar und der guckt zu und der guckt aus dem Fenster raus“. (Warum zieht der an dem Haar?) „Weil der bös' war“. (Was hat er gemacht?) „Die guckt zum Fenster aus. - Ich krieg a Würstche, die Bärbel hat's gesagt“.

\section{Zusammenfassung und Beurteilung}

Früher Beginn im Alter von $7 \frac{1}{2}$ Jahren mit einer für das Alter erstaunlichen produktiven psychotischen Symptomatik (akustische, optische, coenästhetische Halluzinationen, paranoide Wahnideen etc.). Nach etwa 2 Jahren positive Aufwärtsentwicklung von 2⿺辶⿳亠丷厂 Jahren Dauer. Seitdem erstaunlich konstantes monomorphes Bild mit akustischen und optischen Halluzinationen, vor allem imperativen Stimmen, die ihr befehlen, Wäsche und Kleidungsstücke zu zerreißen. Über Jahre hinweg fast ununterbrochen anhaltende akute psychotische 
Aktivität. In den letzten 10 Jahren gibt es auch ruhigere Phasen, in denen die Pat. freundlich und zugewandt ist, aber immer kleinkindhaft läppisch und deutlich kontaktgestört. Seit etwa 2-3 Jahren ist die psychotische Aktivität deutlich geringer geworden, entsprechend sind die Erregungszustände sehr selten geworden, der „Hedemichel“, der ihr die Befehle gab, Wäsche und Kleidung zu zerreißen, ist verschwunden. Stattdessen unterhält sie sich mit „Kurt“ - ein längst verstorbener Patient, der recht gewalttätig war und abgebaut war nach chronischem Alkoholismus. Er und der „Hedemichel“ dürften auch die Funktion von „Phantasiegefährten“ gehabt haben bzw. haben.

Hochgradige familiäre Belastung mit schizophrenen Prozesspsychosen, ausgeprägtes postpsychotisches Residualsyndrom mit infantil-läppischen Verhaltensweisen und starken kognitiven Einbußen.

Bei der konsiliarischen Vorstellung des nachfolgend kurz beschriebenen Mädchens F.A. in meiner Sprechstunde wurde ich an das zuvor dargestellte Krankheitsbild des 7-jährigen Mädchens erinnert und gelangte auf diese Weise zur diagnostischen Einschätzung, dass es sich bei F.A. ebenfalls um eine sehr früh beginnende kindliche Schizophrenie handele. Durch die stationäre Behandlung konnte die Einschätzung bestätigt werden.

\section{Familienanamnese}

Die Großmutter väterlicherseits leidet seit dem Jugendalter an einer rezidivierenden Schizophrenie, welche längere stationäre Behandlungen erforderlich machen.

Psychomotorische Entwicklung: unauffällig

\section{Prämorbid}

unauffällig, durchschnittlich intelligent, gute Schülerin, kontaktfreudig, spielte mit Interesse am Computer der Großmutter

Beginn: akut

Erkrankungsalter: 8 Jahre

Psychopathologisches Bild

Das Mädchen wurde kurz vor dem 7. Lebensjahr eingeschult. Im 1. Schuljahr bestanden überhaupt keine Probleme, F. sei gut mitgekommen. Auch im 2. Schuljahr ging es zunächst gut. Bei einem IQ-Test habe sie einen Wert von 98 Punkten erreicht.

Im Alter von 8 Jahren kam es plötzlich zu einer Wesensänderung: Zunehmende Ängstlichkeit und Misstrauen. Das Mädchen äußerte, von einem „Jimmy“ bedroht zu werden („der Jimmy bringt mich um, der Jimmy will mich verschleppen ..."). Sämtliche Fenster und Türen mussten deshalb geschlossen werden. Für beruhigende Erklärungen war das Mädchen völlig unzugänglich.

Diese Phase habe ungefähr 2 Monate angedauert. Danach trat eine „Ruhephase“ ein. F. war jedoch mutistisch, lächelte immer wieder grundlos und zeigte Lachanfälle. Sie sei „in sich gekehrt" gewesen, manchmal "nicht ansprechbar", habe nicht auf Ansprache reagiert. Aus heiterem Himmel seien immer wieder Wutanfälle aufgetreten mit Schreien oder Lachen, stets etwa 5 Minuten lang anhaltend. Auch starrte das Mädchen immer wieder vor sich hin, auf Fragen reagierte es mit „weiß ich nicht“. - Eine ambulant durchgeführte EEG- und CT-Untersuchung ergaben keinen pathologischen Befund. 
Ein halbes Jahr später kam es zu einer Verschlechterung. F. suchte ihre „weißen Buffalo-Schuhe“, obwohl sie solche Schuhe überhaupt nicht besaß und schrie immer wieder: „Ich will meine weißen Buffalo-Schuhe“. Auch behauptete sie, dass andere Kinder ihr einen „weißen Stift" weggenommen hätten, den sie aber auch gar nicht besaß, auch andere Dinge seien ihr gestohlen worden, die sie ebenfalls nicht besaß. F. wurde zunehmend aggressiv, schlug Großmutter, Mutter und den kleinen Bruder, zerstörte Dinge, warf das Telefon durch die Gegend und geriet immer wieder ohne Anlass in Wut- und Erregungszustände.

Im Alter von 81/2 Jahren veränderte sich die Sprache: Das Mädchen benutzte keine ganzen Sätze mehr sondern sprach im Telegrammstil. Zunehmend gebrauchte F. sehr hässliche Schimpfwörter, die die Großmutter nicht wiederholen wollte, die harmlosesten waren: „Pisser“, „Hurensohn“. - auch hier eine frappierende Ähnlichkeit zur zuvor beschriebenen Patientin V.

Auf meine Frage, ob sie sich jetzt besser fühle, antwortete F.: „Besser geworden“. Als ich die Antwort hinterfrage, sagt sie: „Mein Leben“. Spontan zeigt sie auf die Fenster und sagt: „Kenn ich gar nicht“. Auf meine Frage, was sich bei ihr geändert habe, antwortet sie: „Das $d a$ “ und zeigt wieder auf die Fenster. Am liebsten antwortet sie mit „weiß ich nicht“. Auf die Frage, ob sie manchmal Dinge sähe, die man normalerweise nicht sehe, zeigt sie auf die Bücherwand und sagt: „Das da“. Ob sie manchmal etwas höre, was man normalerweise nicht höre? Antwort: „/a“. (Was?) Antwort: „Vogel“. (Was hörst du?) Antwort: „Fliegen“.

Das Schriftbild ist verschnörkelt, auch die Art und Weise, wie sie schreibt, ist sehr auffällig. Sie beginnt mit einem Buchstaben, fährt mit dem darauf folgenden fort und ergänzt dann erst den vorausgehenden.

Im Alter von 9 lahren wurde das Mädchen stationär bei uns aufgenommen. Unter der Medikation kam es zu einer deutlichen Besserung des psychopathologischen Bildes. Das Mädchen hatte häufig Schwierigkeiten beim Aufstehen und bei der Körperpflege und brauchte dabei ständige Unterstützung. Vergleichbar mit dem zuvor beschriebenen Mädchen war auch bei F. ein starker Drang zum unmäßigen Essen zu beobachten. Das Mädchen grimassierte viel und verharrte häufig über längere Zeit still mit einem verklärten Lächeln. Vielfach war es in sich gekehrt und schien mit seinen Gedanken beschäftigt. Selten nahm es spontan Kontakt zu anderen Personen auf, wenn es antwortete, dann nur einsilbig.

Zeitweilig richtete das Mädchen in stereotyper Weise Fragen an die Mitarbeiter, wie „wohnt der katholische Gott in Dortmund?“, „Ist der katholische Gott der stärkste Gott?“, oder „Werde ich mit Fünfzehn ein blonder Teenager und mit Achtzehn eine junge Frau mit braunen Haaren?“. Immer wieder äußerte es angstvoll, ein ihr nur entfernt bekannter junger Mann wolle es im Alter von 15 Jahren mit anderen Männern „verkuppeln“. - 1 Jahr später fragte das Mädchen stereotyp immer die gleichen Fragen wie „Bin ich ich?“ Schließlich fragte sie immer in stereotyper Weise: „Richtig? richtig? richtig?“

\subsubsection{6b}

Nachbeobachtungszeit: 44 Jahre

Familienanamnese: unauffällig

Milieu: Ehe der Eltern geschieden, deshalb Fürsorgeerziehung

Prämorbid

Kontaktarm, überempfindlich, labil, unselbständig, zurückhaltend, guter Schüler 
Erkrankungsalter: 10 Jahre

Beginntyp: akut

Prodrome

Angstzustände, abnorme Körpersensationen („Es brummt in den Knien“.), bizarres Verhalten (steht im Unterricht auf und fragt, ob seine Pulsadern "noch ganz" seien, anschließend Weglaufen). Oder er fragt unvermittelt „ob es Totenköpfe gibt, die sprechen können“. „Hier riecht es so, ist das Gas, ist es giftig?". Zunehmender Rückzug von der Umgebung, zunehmend bockig, aggressiv, unverträglich, Todesängste.

\section{Symptomatologie}

Bedrohtheitserlebnisse, coenästhetische, olfaktorische und akustische Halluzinationen, paranoide Ideen, Vergiftungsideen. Die Coenästhesien waren sehr eindrucksvoll: „Das Herz bleibt stehen. “, „Der Bauch ist offen. “, „Der Nabel platzt.", „Das Geschlecht geht entzwei. “, „Ein Blitz geht durch mich durch“. Der Junge sah Bilder, sah schwarze Augen, die ihn verfolgten. Er hörte eine Frauenstimme und fühlte sich von anderen Kinder bedroht, zu denen er u.a. sagte: „Ihr könnt nichts als einen Herzkranken schlagen". Er verweigerte die Nahrung, weil das Essen vergiftet sei. Immer wieder zeigte er Wut- und Trotzreaktionen. Während er früher fleißig war, wurde er jetzt faul, spielte nicht mehr mit anderen Kindern und beschäftigte sich nur noch mit einem Faden und einer Rolle. Er schien bedrückt und äußerte immer wieder, dass er herzkrank sei. Nachts rief er mehrmals die Nachtschwester und sagte ihr, er könne nicht mehr richtig schlucken, oder ein Apfel, den er abends zuvor gegessen habe, werde immer dicker und er müsse daran ersticken. Nach insgesamt 6 Monaten Spontanremission: Der Junge war aufgelockert, freundlich, kontaktfreudig, gemütsmäßig schwingungsfähig und ausgeglichen.

\section{Weiterverlauf}

In der Folgezeit lebte der Junge wieder im Jugendheim, da die Mutter eine ausreichende Erziehung nicht gewährleisten konnte. Dort fiel er gelegentlich durch Einordnungsschwierigkeiten auf, war etwas verträumt und zurückhaltend, sonst jedoch unauffällig. 7 lahre später, im Alter von 18 Jahren, traten deutliche Verhaltensauffälligkeiten auf: er wechselte häufig Stellen und Wohnort, es kam zu tätlichen Auseinandersetzungen mit der Mutter und zu kleineren Delikten: er fuhr beispielsweise ohne Erlaubnis mit einem fremden Auto. Im Alter von 19 lahren wurde er von Prof. Stutte gesehen: „Er wirkte etwas phlegmatisch, modulationsarm, aber durchaus rapportfähig. Er berichtet von gelegentlichem Stimmenhören, wirkte aber insgesamt komponiert und nur bei Kenntnis der Vorgeschichte waren die leichten Wesensauffälligkeiten des jungen Mannes als postpsychotische Charakterveränderungen zu deuten".

Zur gleichen Zeit entwich der Jugendliche erneut aus dem Jugendheim, die darauffolgenden lahre reiste er mit Schaustellern herum und hatte keinen festen Wohnsitz. Im Alter von 21-23 Jahren wurde der Patient straffällig, er beging immer wieder Diebstähle, die ihm u.a. 4 Monate Gefängnis einbrachten. Er stahl beispielsweise die Strickjacke seiner Wirtin! Im Alter von 23 lahren äußerte er wiederholt paranoide Gedanken (z.B. sein Meister sehe ihn so komisch an). Er hatte den Kontakt zu anderen Menschen völlig verloren. 1 Jahr später war er wieder in Strafhaft. Dort fiel er durch sein stilles, ratloses, verträumt wirkendes Wesen und seine verschrobene Redeweise auf. In den letzten Tagen der Haft begann er plötzlich das Inventar seiner Zelle zu demolieren. Daraufhin wurde er in eine Beruhigungszelle gebracht, wo er sich freundlich, ruhig und still verhielt. In seine ursprüngliche Zelle zurück- 
gebracht, führte er in den Nacht die Totalzerstörung seiner Zelleinrichtung einschließlich des Wasch- und WC-Beckens fort! Am nächsten Tag zeigte er sich zufrieden und erfreut über den „Erfolg“ und konnte keinen Grund für sein Tun angeben, das er bis zum letzten Augenblick stillvergnügt fortgesetzt hatte. Er wurde daraufhin in ein psychiatrisches Krankenhaus verlegt. Dort gab er an, dass er sich beeinflusst fühle, die Gedanken würden ihm aufgezwungen; „da waren wieder die Stimmen da, die sagen, dass ich das alles auch noch kaputtmachen sollte". Er sprach mit leiser, monotoner Stimme, verhielt sich ruhig, sprach gelegentlich vor sich hin, saß tatenlos an seinem Platz herum, verweigerte die Nahrung; rief plötzlich um Hilfe, weil er sich von Mitpatienten bedroht fühlte, die ihn ergreifen und die Kehle zudrücken wollten und die auch über ihn sprachen. Sein Verhalten war teilweise läppisch-hebephren, teils negativistisch. Er hatte Angst, vergiftet zu werden, und erklärte, es seien ihm "Gedanken eingegeben“ mit dem Inhalt, nichts zu essen. Es liege eine „Fernwirkung" vor. Sein Denken war zerfahren. Er klagte über merkwürdige abnorme Cönaesthopathien: „Ihre Stimmen fielen auf mich. Ich hatte so viel Strahlen in mir, ich war ganz hell im Gesicht. Da war ich mit einem mal mit allen Köpfen verbunden“. Er habe „Auswüchse am Kopf" gehabt, hatte "Strahlen am Kopf". Sein Gedankengang war verstiegen und uneinfühlbar („,ich hätte einen Menschen umbringen können. Wenn ich auf ein Gänseblümchen gesehen habe, wurden die anderen ganz hell.“ Und „mit Strahlen kann man einen Menschen umbringen, das hat man auch schon bei mir gemacht. Innerlich war ich damals ganz verbrannt. Der hat mich aber auch wieder ganz normal gemacht durch sein Sprechen. Die Worte, die ich rausgebracht habe, hat er mir anders wieder reingesetzt. Da hat mir das Leben wieder Spaß gemacht“). Bei der Zerstörung seiner Zelle habe er Stimmen gehört: „Bring sie um mit deinen Strahlen“. Ein Mithäftling habe damals etwas an seinem Körper gemacht, dass er habe wieder essen können. Manchmal habe er auch nicht essen können, weil er eine "Fernsprechung" empfunden habe.

Zum Zeitpunkt der ersten Katamnese lebt der Patient immer noch in einem psychiatrischen Krankenhaus. Es besteht eine deutliche schizophrene Persönlichkeitsabwandlung mit schrullig-sonderlingshaftem Gebaren, Kontaktlosigkeit, Antriebsarmut und affektiver Leere. Seine Antworten sind einsilbig, sein Blick ist ausdruckslos. Er ist still, zurückgezogen, ruhig, umgänglich und zeitweise auch arbeitsam. Gelegentlich kommen Unruhe- und Erregtheitszustände vor mit Fluchtversuchen und sinnlosen und teils gefährlichen Impulshandlungen, in denen der Patient unter dem Einfluss imperativer akustischer Halluzinationen steht. Zeitweise meint der Patient, dass er hypnotisiert werde. Er könne seine Gedanken nicht mehr zusammenhalten. Man könne aus seiner Hand lesen, dass er getötet werden solle. An seine Angehörigen schreibt er teilweise recht verworrene Briefe, in denen er sie u.a. bittet, ihn nicht mehr zu besuchen. Die postpsychotische Persönlichkeitsveränderung hat in den letzten Jahren zugenommen.

\section{Epikrise}

Der Patient ist im frühen Alter von 10 Jahren an einer phänomenologisch sehr eindrucksvollen schizophrenen Episode erkrankt, die voll ausheilte. 7 lahre war der Patient praktisch unauffällig! Erst dann setzte allmählich eine langsam zunehmende Persönlichkeitsveränderung ein, die ein immer typischeres schizophrenes Kolorit erhält. Die teilweise kriminellen Handlungsweisen des Patienten sind absurd, verstiegen, schließlich ist der Patient so auffällig „verrückt“, dass er in ein Psychiatrisches Krankenhaus überwiesen wird. Dort schildert er in eindrucksvoller Weise seine psychotischen Symptome und scheint das Gefühl der Leere, das in ihm entsteht, zu spüren: „Innerlich war ich ganz verbrannt“. 


\section{Katamnese und Nachuntersuchung 44 Jahre nach Krankheitsbeginn, Alter des Patienten 54 Jahre}

Seit nunmehr 30 Jahren ist der Patient dauerhospitalisiert. Phasen stärkerer psychotischer Aktivität mit vorwiegend paranoid-halluzinatorischer Symptomatik und Denkstörungen (Typ I nach Crow) wechseln ab mit Phasen vorherrschend negativer Symptomatik (Antriebsverarmung, Zurückgezogensein, Negativismus, Autismus, Desinteresse, Apathie - Typ II nach (row). 44 lahre nach Erkrankungsbeginn besteht eine floride paranoid-halluzinatorische Symptomatik mit optischen, akustischen und coenästhetischen Halluzinationen, Gedankenlautwerden, Denkzerfahrenheit und paranoiden Bedrohtheitsideen.

Der Patient ist ein schmächtiger, blasser, mittelgroßer Mann mit etwas schütterem, schwarzem Haar. Er ist stets freundlich und zugewandt. Das Auffälligste an ihm ist, dass er immer wieder über längere Phasen hinweg unverständliche Sätze von sich gibt. Diese sind logorrhoeisch, ohne gedankliche Kohärenz. Er spricht von einem kleinen Kind, „das noch keine Bewegungen machen kann, heute passt mir der Tag nicht“.

Auf die Frage, wie es ihm gehe, antwortet er „ganz gut“. Er spricht dann ohne Zusammenhang vom Tod. Auf die Frage, ob er Angst vor dem Tod habe, sagt er: „Keine Angst, ich hab nur Angst, dass mich keiner rettet".

Der Patient spricht fortlaufend nuschelnd vor sich hin, u.a.: ,... wenn du mit dem Kopf runterfällst, das haut nicht hin“. Auf meine Frage, was er gerne mache, sagt der Patient überlegend: „Was soll ich denn sagen, Zigarettengeld, das Sven neulich hatte ... wenn ich nachts aufstehe, ist die Flasche leer".

Bei der Nachuntersuchung äußerte der Patient paranoide Verfolgungs- und Beeinträchtigungsideen. U.a. glaubte er, ermordet zu werden. Der Affekt war inadäquat zum Inhalt des Gesagten (Parathymie). Das Denken war ausgesprochen zerfahren und alogisch. So antwortete er auf die Frage, weshalb er in der Klinik sei: „Weil die ganzen Menschen um mich 'rum sind, die sprechen etwas, in der Zelle essen, da ist man allein, wenn die Menschen nicht mehr um einen 'rum sind, dann stirbt man.“ Der Patient sprach von Gedanken, die „im Kopf laut werden“ und sagte dazu: „|a, das piept manchmal so, das Beten ist so, es sind Menschen da, die beten können, genau wie die ein Gebiss 'runterholen aus den Wolken, da muss einer kommen, was ich für einer bin“. Er höre Stimmen („Ach so, ins Ohr rein, was erzählen, vom Fernsehen was ins Ohr 'rein, noch 1700 lahre ..."). Gelegentlich halluziniert er optisch und wohl auch coenästhetisch („Der Apfel ist im Bauch und die Banane ist die Nase“). Er fühle eine „Kugel im Bauch“, verlangte deshalb immer wieder, am Bauch operiert zu werden. Er fühlte sich von fremden Mächten gesteuert: „Die steuern mich in meinem Bauch und wollen mich umbringen“. „Du hast mir eine Kugel in meinen Bauch gesteuert“, „Meine Mutter soll in Zukunft zu Hause bleiben, die steuert mir dauernd in meinen Bauch und ihre Stimmen, die ich dauernd höre, kann ich nicht mehr ertragen“. Auffallend waren sinnlose Aneinanderreihungen von Hauptwörtern, teilweise in Form von Wörterketten („object chaining“, Maher 1993), so z.B.: „Tausend, tausend, tausend, eintausend, ja, ja, also, ach, ja, ja“ oder „Zeigen, schimpfen, schreien, ich kann's nicht mehr sprechen, zeig' doch, ich zeig's ja auch ... ich komm' wieder auf die Welt, ich komm' wieder, das Unkraut vergisst sich nicht, das kommt immer wieder, Unkraut, Unkraut, Jacobs Krönung, Unkraut, schmeckt auch“, „es müsste mehr Bäume geben, der Apfelbaum reicht nicht aus, Tomate, Johannisbeeren, Himbeeren, Erdbeeren, Stachelbeeren ..." (s.a. Kap. 5.2.3 u. 5.2.7).

Auf meine Frage, was er über das Leben denke, antwortete er: „Ich krieg keinen Bescheid, weil ich zu dumm bin, das kann man mit Kugeln nicht lösen, man muss alt werden“. (Fra- 
ge: Sind Sie in irgendeiner Weise anders als andere Menschen?) Antwort: „|a das merk ich immer, das gefällt mir auch". (Frage: Was unterscheidet Sie von anderen Menschen?) Antwort: „Das Richter geben, das hab ich nicht gleich rausgehabt, du lieber Gott, ... die sind alle abgehauen, der frisst uns auf, bleib hier, bleib hier, erst mal nicht, erst das Mädchen und ich möchte's nicht zeigen, schimpfen, Schwein, ich kann's nicht mehr sprechen, zeig' doch, ich zeig's ja auch.“ Er lacht und klatscht in die Hände. (Es ist also gefährlich): „Was?“ (Dass Sie jemand auffrisst?) Antwort: „Ach so, ja, wenn der wiederkommt auf die Welt, ich komm' wieder, das Unkraut vergisst sich nicht, das kommt immer wieder, Unkraut, Unkraut, Jacobs Krönung, Unkraut schmeckt auch".

Beim Sprichwörterdeuten gibt der Patient a-logische Antworten, die Assoziationen sind so gelockert, dass die Sinnkontinuität völlig verloren geht (s. Kap. 5.2.3 mit Sprachbeispielen des Patienten).

Ein weiteres Beispiel zum Sprichwort "Morgenstund hat Gold im Mund“ sagt der Patient: „Ist deine Brille, da kriegst du bessere Augen, da ist der liebe Gott und da kannst du besser sehen, da werden die Augen zum richtigen lieben Gott" - bei dem Gespräch mit dem Patienten habe ich meine Goldrandbrille auf, was ihn wohl zu diesen Assoziationen veranlasst.

Typisch und wichtig ist eine Beobachtung, die mir vom Stationspfleger mitgeteilt wird: Das Kippen von der Realität im praktischen Alltag in eine „Nebenrealität“, in der der Patient psychotisch, denkzerfahren ist, ohne Punkt und Komma spricht, Wahnthemen äußert, die mit Verfolgung, mit Töten, mit Beeinträchtigung zu tun haben oder mit einer Kugel im Bauch. Andererseits reagiert der Patient völlig realitätsadäquat, er denkt an seine Arbeit in der Küche, die er rasch und schnell und trotzdem ordentlich verrichtet. Er möchte allerdings niemand dabei haben, fühlt sich von anderen schnell bedroht oder in die Enge getrieben. Deshalb muss er in der Küche seine Arbeit allein verrichten. Man kann ihn auch mit viel Geld zur Sparkasse gehen lassen, er erledigt die Aufträge gewissenhaft und problemlos!! Das heißt also: das psychotische Wahnbild steht unvermittelt neben der alltäglichen Welt!

Auffallend ist, dass der Patient praktisch seit Jahrzehnten kontinuierlich psychotisch ist mit Wahnsymptomen, akustischen, optischen und coenästhetischen Halluzinationen und Denkzerfahrenheit, dass er andererseits aber in der Realität recht gut zurecht kommt und seine Aufgaben und Pflichten zufriedenstellend erfüllt. Er arbeitet sehr geschickt, schnell und trotzdem ordentlich, er malt den ganzen Tag. Er geht gern spazieren, kauft ein, außerdem raucht er gerne und trinkt auch gern Kaffee, kann im Zweierkontakt recht gesellig und zufrieden sein, man darf ihm allerdings nicht zu nahe kommen, weder physisch noch psychisch, hier bestehen große Ängste, er fühlt sich rasch in die Enge getrieben, vielleicht sogar bedroht. Bei Mitpatienten, bei Pflegern und einer Psychologin kann es zu eruptiven Gewalttätigkeiten mit erheblichen Verletzungen kommen.

\section{Diagnose}

Schizophrenie vom paranoid-halluzinatorischen Typ (DSM-IV 295.30, continuous course. ICD10: F 20.00). Schweres Residuum (DAS-M-3: 5).

Therapie: Neuroleptika 


\subsubsection{6f}

Nachbeobachtungszeit: 44 Jahre

Familienanamnese: unauffällig

Milieu:

Vater unehelich geboren. Ehe nach 18 Jahren geschieden. Mutter lebt mit verheiratetem Mann zusammen, von dem sie ein Kind hat (Totgeburt)

Psychomotorische Entwicklung: unauffällig

Prämorbid

Gute Schülerin, nicht sitzen geblieben, kontaktschwach, sondert sich ab, Einzelgängerin. Singt gern, hängt sehr an der Mutter. Bei Schulaufgaben sauber und ordentlich

Erkrankungsalter: 12 Jahre

Beginn: akut

\section{Symptomatologie}

Das Mädchen fühlte sich zurückgesetzt: „Ich muss immer zurückstehen, ich bin wie ein Stiefkind in der Klasse“. Fing plötzlich stark an zu weinen, lässt sich nicht beruhigen. Schläft schlecht, weint viel und schreit viel ohne Grund. Davor maniforme Symptomatologie: lacht inadäquat und unmotiviert in der Schule. Äußert Todeswünsche, sie wolle sterben. Sie spricht nicht (Mutismus), Nahrungsverweigerung. Motorische Erregungszustände. Einmal laut geschrieen und mit Wasser gespritzt, gab als Grund an: Ein Mädchen habe zum Fenster hereingesehen und gesagt: „Das alles kostet 20 Pfennig“, sie habe aber nur 10 Pf. gehabt. In einem solchen Erregungszustand rief sie einmal: „Ihr sollt meine Mutter nicht erstechen“. Sie äußerte, dass sie Vater und Mutter an der Decke höre, „wie sie sich unterhalten“. Außer optischen und akustischen Halluzinationen bestanden weitere Symptome: Steife Haltung, starrer Gesichtsausdruck, Ambitendenz („wenn ich liege, möchte ich aufstehen, und wenn ich aufstehe, möchte ich liegen, ich weiß nicht, was das ist“). Das Mädchen ist zeitlich und örtlich nicht voll orientiert. Es ist ratlos und unsicher. Es kommt schließlich zu hochgradigen Erregungs- und Unruhezuständen, in denen das Mädchen ihre Bücher zerreißt und aggressiv ist, zwischendurch weint und jammert. Es klagt über abnorme Körpersensationen: Der Kopf würde immer länger und größer, es verspüre ein „Schütteln im Körper“. Immer wieder kommt es zu solchen Unruhezuständen mit Aggressionen, das Mädchen wirkt affektiv leer und lacht immer wieder unmotiviert. Während der stationären Behandlung erzählt es der Krankenschwester, dass es wegfahren und einen „Raubmord“ begehen wolle, später ohrfeigt das Mädchen die Schwester. Das Denken ist zerfahren, das Mädchen berichtet über imperative akustische Halluzinationen. So habe ihr eine Freundin gesagt, sie müsse durch das Fenster springen, sonst würde sie getötet. „Sie hat es ganz laut zu mir gesagt in der Nacht heute“. Außerdem litt das Mädchen unter der Vorstellung, man wolle ihr „den Bauch aufschlitzen" und äußerte, dass sich ihre Mutter habe peitschen lassen. Immer wieder hörte sie ihre Mutter sprechen und sagte wörtlich: „Das Welttelefon hat zu mir gesprochen“. Oft steht das Mädchen stundenlang herum und schreit, ist dabei völlig unbeeinflussbar, hat keinen Kontakt zu anderen Kindern und halluziniert heftig.

Liquoruntersuchung: unauffällig. 


\section{Pneum-Encephalographie: Hirnrindenatrophie.}

Nach einer Behandlung mit 14 Elektroschocks und 13 Insulinkomata kommt es zwar zu einer Beruhigung der Symptomatik, das Mädchen ist aber sexuell stark enthemmt. U.a. zeigt es seine Brüste, küsst die Ärztin, liegt eines Morgens nackt im Bett und drückt sich die Brüste, das Mädchen halluziniert weiter und ist paranoid. Es bestehen deutliche Defizienzzeichen wie Antriebsarmut und Affektlahmheit.

Dauer der ersten psychotischen Episode: 5 Monate.

Katamnese und 1. Nachuntersuchung (15 Jahre nach Erkrankungsbeginn, Alter der Patientin 27 Jahre)

Nach der ersten psychotischen Episode war die Patientin zunächst 5 lahre lang frei von psychotischen Erlebnissen. Sie hat zunächst 2 Jahre lang die Volksschule besucht, diese glatt durchlaufen und war anschließend bis zum Alter von 17 Jahren auf der Gewerbeschule, sie habe „Büffetfräulein“ werden wollen. Da habe sie aber zu wenig verdient und habe deshalb eine andere Stelle angetreten. Von da ab sehr häufiger Stellenwechsel, u.a. hat sie als Botin und als Putzfrau gearbeitet. Die einzelnen Stellen kann sie nicht mehr nennen, sie hat jeweils nur einige Wochen bis Monate lang an einer Stelle gearbeitet.

Im Alter von 21 Jahren Heirat. Nach 3 Jahren Scheidung. Keine Kinder aus dieser Ehe. Später habe sie einen anderen verheirateten Mann kennen gelernt, von dem sie ein Kind (Helmut) bekommen habe. Diesen Mann habe sie aber nicht geheiratet. Sie sei jetzt ledig. Während der Schwangerschaft habe sie in einem Nähereibetrieb gearbeitet. Schwangerschaft und Geburt seien unauffällig, ohne Komplikationen verlaufen. Sie habe während dieser Zeit auch keine besonderen psychischen Störungen gehabt. Jetzt sei sie arbeitslos, bekomme Unterstützung von der Wohlfahrt, sie widme sich ganz ihrem Kind.

Als Begründung für den häufigen Stellenwechsel gab sie an: „Wegen dem Zanken“, „ich musste immer gehen für die anderen“. Sie habe geglaubt, dass die anderen ihr die Arbeit wegnehmen und sie verdrängen wollten, sie fühlte sich durch die anderen beeinträchtigt und verfolgt. Sie höre die anderen hinter ihrem Rücken über sie sprechen. Sie sagt dazu: „Ich habe keine Zeit dazu gehabt, ich bin dann vorbeigegangen, vorbeigegangen, ne“ (Danebenreden).

Bei der ersten Nachuntersuchung im Alter von 27 Jahren gab sich die Patientin zunächst ängstlich-scheu, schien misstrauisch und verstört und versteckte sich hinter ihrer Mutter, dabei nervös an einer Zigarette rauchend. Ihre Mimik war auffallend starr und ausdruckslos; nur ab und zu kam durch ein völlig unmotiviertes steifes und verzerrtes Grinsen oder auch Lachen Bewegung in das Gesicht. Haltung und Bewegungsablauf waren steif und eckig. Ein echter, warmer Kontakt zur Patientin war nicht herzustellen, ihre emotionale Schwingungsfähigkeit schien erheblich herabgesetzt, ihre Affektivität war starr, kalt, leer und öde. Sie sprach mit monotoner, undeutlicher, schlecht artikulierter Stimme, sehr hastig und nervös, einzelne Silben verschluckend. Sie sprach auch nicht von selbst, sondern nur, wenn sie angeredet wurde und erschien dann verstört, fast verwirrt. Auffallend war ihre Neigung zum Danebenreden, z.B. antwortete sie auf die Frage nach ihren Stimmungen: „mal böse“ und nach einer kurzen Pause "dann bekommt das Kind einen Klaps“ - „kann das aber nicht immer machen“ - „es muss schlafen, wenn es müde ist“ - „bis man das mal spitz hat“.

Oft widersprach sie sich in ein- und demselben Satz. Beispielsweise antwortete sie auf eine Frage, die sich auf ihren Antrieb bezog, sie habe seit 5 lahren keine Lust mehr zur Arbeit, der Schwung sei noch da, „wenn ich überfröhlich bin, gehe ich mehr an die Arbeit 'ran, besonders, wenn ich erkältet bin“. Ja, wenn sie erkältet sei, habe sie mehr Schwung. Man gewann den 
Eindruck, dass die Patientin mit sich selbst beschäftigt war während des Gesprächs und dass sie abwehrend unüberlegte, falsche Antworten gab. So sagte sie z.B., dass sie seit 2 Jahren in dem Hause wohne, in dem sie in Wirklichkeit seit ihrer Kindheit lebt. Oder auf die Frage, ob sie manchmal innerlich unruhig sei, antwortete sie „nein, nie, nur heute $1 / 2$ Stunde“ (Öfters?) "Nein, öfters, nur öfters“.

Zu ihrem Kind, das sie mechanisch an- und auszog, schien sie keine spürbare innere Beziehung zu haben. Selbst - was selten vorkam -, wenn sie das Kind ab und zu streichelte, wirkte sie seltsam starr und kalt dem lebhaften und zugewandten Jungen gegenüber, der affektiv leicht ansprach. Auf die Frage, was sie bei einem etwaigen Tod ihres Kindes empfinden würde, antwortete sie ohne sichtbare affektive Beteiligung: „Dann würde ich ihn beerdigen lassen“. Weder zu Menschen, Tieren oder Pflanzen habe sie irgendein Verhältnis, sie habe keine freundschaftlichen Beziehungen zu irgendeinem Menschen und weder Freunde noch Freundinnen.

In ihrer Wohnung war es unvorstellbar unordentlich und unsauber. In ihrer Arbeit erschien sie sprunghaft, ohne Ausdauer, im Antriebs- und Willensbereich bestimmbar, wenig eigenständig, ziellos und spannungsarm. Sie ist Kettenraucherin.

Die Frage, ob sie gern lebe, wurde bejahend beantwortet, dies jedoch ohne überzeugende affektive Beteiligung. Schließlich sagte sie: „Warten Sie mal ab, umgebracht will ich doch nicht werden." Zu Hause bleibe sie nicht gerne, sie wolle nicht gerne allein sein, sie gehe gern in die Wirtschaft und rauche und trinke. In letzter Zeit allerdings weniger, da kein „Mann da“ sei, der sie begleite, „obwohl es mir jetzt nichts mehr ausmacht“. Abends gehe sie nicht fort, da habe sie „Angst, ich könnte ins Auto gezogen werden“. Auf die Frage nach ihrer Lieblingsbeschäftigung antwortete sie: „Heiratsbeschäftigung, Heiratsanzeigen, besonders kurz vor der Heirat“. - Und: „Jetzt Herumsitzen, Radiohören“ (Was?) „Was gesprochen wird da drin und auch mal Schlager". Im Grunde habe sie keine Lieblingsbeschäftigung, nichts, was ihr Freude oder Spaß bereite. Richtige Zukunftspläne habe sie ebenfalls nicht. Wenn ihr Sohn in den Kindergarten gehe, wolle sie selbst wieder arbeiten gehen, „was in die Hände fällt“.

Nachdem die Patientin zunächst ängstlich-misstrauisch und abweisend war und sie überempfindlich reagierte, wenn das Gespräch ihre Erkrankung und ihre Person berührte (,ich bin gesund, mir fehlt nichts, es ist alles in Ordnung "), wurde sie im Laufe der Unterhaltung zunehmend auskunftsbereiter, ohne dass allerdings der Kontakt besser wurde oder die Resonanz zunahm. Sie gab an, alle paar Monate unter Angstzuständen zu leiden. Sie fühle sich durch die Mitmenschen beeinträchtigt, bedroht und bedrängt; sie höre sie hinter ihrem Rücken über sie sprechen. Nach Stimmen befragt, gibt sie an: „Kann ich net drüber sprechen, sonst glaub' ich ja“. Sie wird verlegen, wehrt ab, bekommt einen roten Kopf. Schließlich gibt sie an, dass Sie Stimmen höre, die über sie sprechen. Auf die Frage, ob sie auch etwas sehe, was in Wirklichkeit gar nicht da sei, antwortet sie: „|a, ich sehe Menschen, einen Mann oder eine Frau“. (Frage: Sprechen sie?) Antwort: „ןa, das ist das von der Decke“. So sah sie wenige Tage zuvor „einen Mann und eine Frau an der Decke sich miteinander unterhalten“ und hörte „das Welttelefon sprechen“. Die Gespräche seien „immer verschieden“, es sei „nicht immer dasselbe", was gesprochen würde. Sie sei alle paar Wochen gereizt, verstimmt, erregt und nehme dann keine Nahrung zu sich. Sie rege sich überhaupt schnell auf und ärgere sich leicht. In diesen Zeiten wechsle sie dann die Stellung oder bleibe von der Arbeit fort „wegen des Zankens“, „ich musste immer gehen für die anderen“.

Einige Testfragen, welche ich bei der Nachuntersuchung stellte, deckten ebenfalls die eigenartige Denkstörung der Patientin auf. Die Patientin definierte den Unterschied zwischen 
einem Teich und einem Fluss folgendermaßen: „Der Teich ist mit Sand besät, der Fluss ist im Wasser und wenn man das Wasser mit dem Feuer zusammentut, ist es dasselbe“ - „beides ist gefährlich, ich weiß was gemeint ist, aber wie das zusammenhängt, weiß ich auch nicht". Andere Begriffsbestimmungen konnten ebenfalls nicht richtig und sinngemäß gegeben und das Wesentliche nicht formuliert werden. Über den Sinn des Sprichwortes „Morgenstund hat Gold im Mund“ befragt, gab sie zur Antwort: „Morgens darf man nicht singen oder pfeifen, sonst gibt's was Schlechtes zu hören“. (Wieso?) „Vom Meister eine verpasst“. Mit dem Wort Gold sei gemeint: „Von morgens 5 Uhr bis 7 Uhr bedeutet das“. So trat eine Störung der Sinnerfassung zutage, eine Denkstörung - unterscheidbar vom gewöhnlichen Schwachsinn oder von der organischen Demenz -, welche die in Kapitel 5.8 beschriebenen schizophrenietypischen Besonderheiten aufwies.

\section{Weitere Katamnese}

Nach den Berichten des inzwischen 30 Jahre alten Sohnes der Patientin (zum Zeitpunkt der ersten Nachuntersuchung war er $1 \frac{1}{2}$ |ahre alt) hatte sich das Krankheitsbild wohl sehr gebessert. Er erinnert sich, dass er ganztags im Kindergarten gewesen sei und von der Mutter jeweils abgeholt wurde. Er sei sehr gerne bei der Mutter gewesen und habe sie sehr gerne gehabt. Die Trennung von ihr habe er immer als schmerzlich erlebt. Sie habe ihm „sehr viel Liebe“ gegeben. Seine Mutter sei „ein lebensfroher Mensch“ gewesen. „Sie war immer für mich da". Sie hätten Fahrradtouren zusammen unternommen bis zu $50 \mathrm{~km}$, die Mutter habe viel geraucht. Sie sei ihm immer als "fröhlich und zuversichtlich" erschienen. Er selber sei ein typisches „Schlüsselkind“ gewesen. Schulisch sei er nicht gut gewesen, er habe die Schule geschwänzt, die Schulleistungen seien schlecht gewesen, so dass das Jugendamt eingegriffen habe. Mit $9 \frac{1}{2}$ lahren sei er in ein Kinderheim gekommen, bis zum Alter von 17 lahren. Danach habe er eine Lehre absolviert, sich Arbeit gesucht, er arbeite als Rangierer und Lokführer bei der Bundesbahn.

Bis zum Unfall der Mutter - sie war damals 43 lahre alt - sei seine Mutter „ein richtig lebhafter Mensch" gewesen. Bis zum Unfall habe sie auch 5 lahre lang einen konstanten Freund gehabt, bis dahin nur sehr viele wechselnde Bekanntschaften. Sie sei von diesen „Freunden“ wohl immer nur ausgenutzt worden. Sie sei eine gute Köchin gewesen, habe sehr schmackhaft kochen können. Sie hätten auch viel zusammen unternommen. Seine Mutter habe sich nie etwas gegönnt, sie habe sehr viel Geld angespart, und er sei auch als Junge materiell sehr verwöhnt worden. Sie war wohl immer auf Partnersuche.

Im Alter von 43 lahren erlitt die Patientin einen Autounfall mit einem schweren SchädelHirn-Trauma. Sie ist offensichtlich in ein fahrendes Auto gelaufen! - Interessant ist, dass die Patientin mir 16 lahre zuvor bei der 1 . Nachuntersuchung von ihrer „Angst“ berichtet hatte, „ich könnte ins Auto gezogen werden“.

Seit diesem Unfall bestanden Sprachstörungen und 5 lahre später traten epileptische Anfälle auf. Alkoholismus seit dem Unfall. Im Alter von 64 Jahren wurde die Patientin von ihrem Sohn in bewusstlosem Zustand aufgefunden, vermutlich in einem Zustand nach Status epilepticus, ca. 5 Tage lang andauernd, mit nachfolgendem hypoxämischen Hirnschaden. Danach wurde die Patientin lebensbedrohlich krank mit rezidivierenden Fieberschüben, Knochenmarkentzündung, Durchfällen, intermittierender Porphyrie. Die Pat. brauchte eine 5 Monate andauernde intensive stationäre medizinische Betreuung. Es bestand damals ein schweres Krankheitsbild, es gelang aber schließlich, dass die Patientin sogar Emotionen wie Freude und Trauer durch Gestik und Mimik ausdrücken und bekannte Personen mit 
Handschlag begrüßen konnte. Am Entlassungstag konnte sie sich sogar am Oberkörper selbständig anziehen.

\section{Zweite Nachuntersuchung}

3 Monate später habe ich die Patientin in einem Heim besucht, sie saß zusammengesunken im Rollstuhl, war nicht ansprechbar, sabberte vor sich hin, musste gefüttert werden und befand sich in einem trostlosen Zustand. Sie war tetraspastisch, es bestanden Schluckstörungen, sie konnte nur flüssige oder breiige Nahrung zu sich nehmen und wurde durch die Nasensonde ernährt. Der rechte Schädelknochen war tief eingesunken (Zustand nach Trepanation). 3 Monate später ist die Patientin dann verstorben im Alter von $64 \frac{1}{2}$ Jahren.

\subsubsection{1 a}

Nachbeobachtungszeit: 37 lahre

\section{Familienanamnese}

Mutter der Mutter Suizid im Alter von 36 Jahren.

Bruder der Mutter mit 17 lahren Suizid (Strangulation) nach einem missglückten Suizidversuch, war von jeher sehr verschlossen.

Schwester des Vaters der Mutter Suizid im Alter von 55 Jahren.

Mutter leidet an rezidivierender Schizophrenie, wiederholt stationäre Behandlung.

Der Patient hat noch einen 1 Jahr jüngeren Bruder, der zu Klauereien neigte.

\section{Familienmilieu}

Beide Eltern in erster Ehe geschieden, wollen sich scheiden lassen. Erhebliche zwischeneheliche Spannungen. N. ist außerehelich geboren, Mutter scheint ihren Sohn zu hassen, lehnt inn ab. Vater des Pat.: Straßenmusikant auf der Reeperbahn, Trinker, hat viele Berufe angefangen, nichts beendet.

Eigenanamnese: unauffällig

\section{Prämorbid}

Schüchtern, einmal sitzen geblieben wegen mangelnder Mitarbeit. Durchschnittlich intelligent, lieb, gut führbar, Einzelgänger

Beginn: schleichend

\section{Erkrankungsalter: 9 Jahre}

\section{Symptomatologie}

Der Junge wurde zunehmend scheu, lief immer wieder von zu Hause weg, ohne einen Grund angeben zu können. Eigentumsdelikte ohne Grund, Zerstörungstendenzen, Schulschwänzen, starkes Onanieren. N. verweigerte den Schulbesuch, riss sich von der Mutter weg, wenn sie inn zur Schule bringen wollte, floh in den Wald und baute sich dort Hütten, in die er sich zurückzog. Er war schließlich gefühlsmäßig kaum noch ansprechbar und zog sich völlig von der Umwelt zurück. Er entwickelte eine starke Neigung zu aggressiven Verhaltensweisen. Für sein Weglaufen gab er merkwürdige, verschrobene Begründungen: Es stinke nach Dung. 
Zeitweise traten Angstzustände auf sowie Erregungszustände, er zerreißt dann seine Wäsche und ist aggressiv gegen seine Umgebung. Seine Schrift veränderte sich: Ineinander geschobene Buchstaben, so dass die Schrift kaum leserlich war, jeder einzelne Buchstabe wurde ausgemalt, fast verschnörkelt.

N. sonderte sich zunehmend ab, wurde verschlossen, hörte schließlich völlig auf, sich am Unterricht zu beteiligen, keine Schularbeiten mehr, starke Onanie.

Mit 13 Jahren nahmen die Verhaltensauffälligkeiten zu und machten eine 1-jährige stationäre Behandlung erforderlich. N. unternahm einen Suizidversuch und zeigte erhebliche Aggressionen gegen Mutter und Bruder. Seine Motorik war maniriert - bizarr, die Bewegungen waren eckig-steif. Außerdem kam es zu sinnlosen kleinen Diebstählen, er stahl z.B. die Messingkappe einer Zentralheizung sowie Schnüre einer Wasserspülung vom WC. In den umliegenden Wäldern baute er sich Hütten, in die er sich zurückzog und viel onanierte. Wurde er entdeckt, floh er wie ein gehetztes Wild davon und baute sich an anderer Stelle neue Hütten.

Nachdem er die Mutter und den jüngeren Bruder mit einem Vorschlaghammer angegriffen hatte, wurde er stationär aufgenommen, im Alter von 13 Jahren.

N. war unansprechbar, sprach nicht, war äußerst zurückhaltend, wenn er etwas fragte, hielt er sich die Hand vor Mund und Nase und war nicht zu verstehen. Er stand viel in einer Ecke in verkrampfter Haltung herum. Sein Gesicht war maskenhaft starr.

Der Junge bot ein hebephrenes Bild mit negativen Symptomen, er war äußerst unordentlich in seiner Kleidung, neigte zum Grimassieren. Fragen beantwortete er abweisend „ich weiß nicht“, „,ist mir egal“, er nahm keine Anteilnahme an seiner Umgebung, wirkte affektiv leer und flach, die Mimik ausdrucksarm. Er war misstrauisch-lauernd, kicherte zeitweise ohne ersichtlichen Grund, hüstelte, seufzte, schnalzte und schnaufte.

Schließlich kamen positive Symptome hinzu: Imperative akustische Halluzinationen, die ihn zu wiederholten Suizidversuchen durch Strangulation veranlassten. Er litt unter kataton-stuporösen Zuständen und hörte Stimmen, die zu ihm sprachen und die ihn beschimpften. $\mathrm{N}$. äußerte Beziehungs- und Verfolgungsideen, er hängte deshalb Wolldecken vor die Fenster, schaute immer wieder unter das Bett und die Matratze. Weiterhin entwickelte er Vergiftungsideen und hypochondrische Wahnideen sowie Beeinflussungsideen. U.a. fühlte er sich von Strahlen beeinflusst. Außerdem klagte er über merkwürdige Körpermissempfindungen. So rief er plötzlich beim Spaziergang: „Mein Kopf ist schief, bringen sie mir den doch endlich gerade“. Plötzlich zog er sein linkes Bein nach, drehte sich um die eigene Achse, streckte den linken Arm steif nach vorne und schrie: „Halten sie mich, ich kann nicht mehr, bringen Sie meinen Kopf gerade, mein linkes Bein muss geschient werden“. Dann legte er sich auf die Erde, sprang gleich wieder hoch und rief: „Helft mir doch, mein Rücken muss geschient werden". Zwischendurch lachte er dabei. Dann warf er sich wieder auf die Erde und rief: „Ich will Narkose. Schient mich doch!“ Wenig später schrie er: „Ich habe Nervenkrämpfe, die Schmerzen beginnen wieder, so helfen Sie mir doch!" Abends äußerte er Vergiftungsideen, man habe ihm Gift ins Essen getan, verweigerte deshalb die Nahrung. Sexuell war er stark enthemmt und psychomotorisch unruhig. Immer wieder kam es zu starken Erregungszuständen, in denen er seine Kleidung zerriss.

Die Suizidversuche häuften sich (Strangulation, Öffnen der Pulsadern). Hinzu kamen formale Denkstörungen (Gedankenabreißen, Gedankenlautwerden, Denkzerfahrenheit). So sagte er u.a. „es kommen Worte aus meinem Mund, wenn er zu ist. Das sind meine Gedanken, die laut werden. Ich werde hier spürbar". 
Im Alter von 15 lahren erfolgte eine stetige Besserung, die etwa 3 lahre lang anhielt. N. war arbeitsfähig, ordentlich, sauber, gepflegt, führte sich gut an der Arbeitsstelle (Holzfabrik).

Im Alter von 17\%1/2 Jahren wieder erneute Verschlechterung, der Patient wird zunehmend verworren und sonderbar, führt Selbstgespräche, in seinen Gesprächen ist er sehr sprunghaft, man kann ihm kaum folgen. Er arbeitet als Binnenschiffer auf dem Schiff, hat aber dort Schwierigkeiten, trinkt gelegentlich viel Alkohol und onaniert sehr viel, raucht unmäßig.

Negative und positive Symptome bestehen nebeneinander: Starre Mimik, steife und eckige Bewegungen und Körperhaltungen, undeutliche Sprache, monotone Stimme, Stereotypien, Grimassieren, inadäquates Lachen, „völlig leerer Affekt“, Antriebsarmut.

Daneben bestanden positive Symptome wie Wahneinfälle, Größen- und Vergiftungsideen, a-logische Denkinhalte, abnorme gedankliche Verknüpfungen, Neologismen, Gedankenabreißen und Beeinflussungsideen. Der Patient fühlte sich von einem Magneten hypnotisiert, der u.a. seine Pupille erweitere. Weiterhin litt N. unter Coenästhopathien, verspürte „Schwellschmerz in der Brust", unter diesem Einfluss unternahm er einen Suizidversuch mit Tabletten.

Im Alter von 20 Jahren kam es zu einer Besserung mit Distanzierung von den Wahnideen, die 4 lahre lang anhielt, danach wiederum verstärkt Vergiftungs- und Verfolgungsideen. Das Verhalten von $\mathrm{N}$. wurde zunehmend uneinfühlbar. Nach 2 lahren erneute Besserung, so dass $\mathrm{N}$. im Alter von 28 Jahren entlassen werden und in einem Wohnheim leben konnte. Nach 3 lahren war er jedoch so verwahrlost, dass er wieder stationär aufgenommen werden musste. Im Alter von 33 Jahren kam es zu erneuten paranoid-halluzinatorischen Episoden, welche sich im Alter von 36 Jahren wiederholten und in den Folgejahren anhielten. N. war nur noch in der Lage, leichte Arbeiten auszuführen.

\section{Nachuntersuchung im Alter von 46 Jahren, 37 lahre nach Krankheitsbeginn.}

$\mathrm{N}$. wurde im Langzeitbereich einer psychiatrischen Klinik in Norddeutschland untersucht. Herr K. geht leicht vorne übergebeugt, etwas kleinschrittig, seine motorischen Bewegungen sind etwas verlangsamt. Herr K. leidet unter einem sehr ausgeprägten Zwinkertic, wobei er nach oben oder in eine Ecke schaut, so dass man gelegentlich den Eindruck hat, ob er vielleicht etwas sieht, oder ob er mit seinen Gedanken beschäftigt ist. Auffallend ist seine abgehackte, hastige Sprechweise. Die Sprachinhalte sind teilweise inkohärent und weder inhaltlich noch akustisch verstehbar. Die Sprache wird dann nuschelig, monoton, leise. Bei Nachfragen werden weitere inkohärente Satzbruchstücke aneinandergereiht. Auffallend ist, dass das sprachliche Ausdrucksvermögen bei neutralen Themen unverändert bzw. relativ unauffällig ist und dass bei wahnhaft besetzten Themen das Denken und die sprachlichen Äußerungen zerfahren werden.

\section{Beispiel}

Unvermittelt spricht N. von „Pharmaforschung, Psychologie, in der Form wurde das angewendet bei mir". Das sei schon länger her, „im vorigen Jahr vielleicht“. Der Pfleger habe ihm eine Spritze gegeben, alle 14 Tage, „das Mittel wirkt so langsam durch“. (Frage: Was haben Sie gespürt?) Antwort: „Mehrmals gefoltert worden von außenstehenden Leuten, die gleichartigen Verhältnisse, die Antragsstellung, bei der Anlegung von Spritzen, Lynchjustiz haben die veranstaltet hier, Lynchjustiz“. (Das war sicher ganz schlimm für Sie?) Antwort: „Ganz schlimm, ja“. (Haben Sie sich dagegen gewehrt?) „Wehren, ha, bei der Art und Weise, wenn man sich nicht drauf vorbereitet, ist das schlecht“. (Konnten Sie sich drauf vorbereiten?) „Ne, 
so was von Nebenwirkung von vorbereitenden Spritzen, dass man sich auf die allgemeine ... vorbereiten kann". (Was meinen Sie damit?) Antwort: „Für eine derartige Entmündigung wird in Deutschland die Todesstrafe eingeführt“. (Sie fühlen sich entmündigt?) Antwort: „Das ist der Fall, dass ich der psychologischen Anstaltsbildung unterstehe". (Was kann man da tun?) Antwort: „Nur, wenn ich entlassen werde, kann die Entmündigung aufgehoben werden“. (Sie würden gerne entlassen werden?) Antwort: „, a klar, ja. Die chemische Zwangsjacke darf in dem Sinne nicht angewendet werden“. (Frage: Was könnte man tun?) Herr K. ist ratlos, zuckt heftig mit den Augenlidern und sagt schließlich: „Ich bin der Meinung, dass in dem Fall die Gesetze aufrechterhalten werden müssen, die Paragraphen".

Optische und akustische Halluzinationen werden negiert. Herr K. sagt, dass bei „Halluzinationen pharmazeutische Mittel“ eine Rolle spielten, „die Mittel legen sich auf die Augen und spiegeln sich durch die Augen, dass man was sieht, rote Flecken z. B“. Er fühle sich hier „ekelhaft kontrolliert".

Herr K. spricht vom „, seelischen Schmerz“, „,von überdurchschnittlicher Bildung“, „Spannung im Kopf, jetzt ist das so, dass die allgemeine Verspannung durch die Bildung ...". Es ist nicht verständlich, was Herr K. mit diesen Satzbruchstücken meint, die ohne erkennbaren inneren Zusammenhang aneinandergereiht oder durch unverständliches Gemurmel miteinander verbunden werden. Auf die Frage, wie er sich fühle antwortet er: „Etwas differiert“. (Wie meinen Sie das?) „|a, gesundheitlich“. (Wie ist Ihre Stimmung?) „Allgemeinbleibend, ist allgemeinbleibend". Schlaf und Appetit seien gut, manchmal habe er jedoch noch keinen Appetit. (Wovon hängt das ab?) Antwort: „Was soll man dazu sagen, von Allgemeinkost oder Schonkost vielleicht“. (Was ist Ihr größtes Problem?) „)a, ich soll ja demnächst mal entlassen werden“. Zurzeit werde er auf eine Reha-Maßnahme vorbereitet. Es wäre ihm aber lieber, entlassen zu werden. (Was würden Sie machen, wenn Sie entlassen werden?) Antwort: „|a, ich bekäm' vielleicht ein Angebot auf dem Arbeitsamt“. (Was würden Sie gern machen?) „Ich könnt' vielleicht einen Gewerbeschein beantragen“. (Früher waren Sie mal bei der Binnenschifffahrt?) Antwort: „Es ging ziemlich gut“. (Wo waren Sie da?) „Im Ruhrgebiet, in Holland, in Bremen, auf dem Rhein“. (Wie lange?) „2 lahre“. (Warum haben Sie da aufgehört?) „Weil ich magenkrank wurde“. Er sei dann 1/4 Jahr im Krankenhaus gewesen. (Frage: Warum sind Sie hier?) Antwort: „|a, ich wurde wegen nervlicher Störungen hier eingewiesen. Ich habe an nervlichen Amokanfällen gelitten, aber ohne ..., nicht so wie Amoklaufbahn, sondern nervliche Schmerzenden und Wahnsinnszustände“. „Das war, dass mir jemand eine Giftspritze versetzt hat". (Frage: Gibt es jemand, der Ihnen was Böses will?) Antwort: „Was soll man da sagen?" Er schweigt und sagt dann: „Das könnte man vermuten“. Unvermittelt fragt er mich dann, „ob ich von jemandem beauftragt" sei, „um meine Auffassung, meine Bildung zu prüfen", die sei völlig normal.

(Frage: Kennen Sie jemand, den Sie gerne mögen?) Antwort: „Ich kenn niemanden weiter". (Lebt Ihre Mutter noch?) „Nein, sie lebt nicht mehr“. Sie sei in den letzten Jahren an Altersschwäche gestorben. Verwandte habe er nicht mehr. Nach dem Bruder befragt, meint er, über den wisse er nichts, er interessiere sich auch nicht für ihn, es könne sein, „dass er im Zuchthaus sitzt“. (Weshalb?) „Wegen der allgemeinen Beteiligung-Rauschgift“. (Was meinen Sie damit?) Antwort: „Ich wurde doch nur bestohlen von diesen Leuten“ (Sind die hier eingedrungen?) Antwort: „Kann man schon behaupten“. (Hat das denn niemand verhindert?) Antwort: „Kann man nicht so genau feststellen, sind ja auch Gewalttäter, vielleicht auch durch Bestechung, hätte man vielleicht vermuten können, kann man nicht so genau übersehen". „Bin ja von den Leuten gefoltert worden, die sich unter den Antrag der Einweisung gestellt haben“. (Frage: Wie das?) Antwort: „Das wurde gewaltsam durchgeführt“. (Frage: Bei Ihnen?) 
„|a“. „In Hannover wurde ich von einem Pfleger mit der Pistole bedroht, da wurde eine Spritze in den Körper gestochen“. (Werden Sie jetzt auch noch bedroht?) Antwort: „Das ist die relative Entwicklung unter der ich noch in der Anstalt bin, das sind so komische Gefühle, da muss ich vorsichtig sein, das sind so chemische Mittel, über physische oder chemische, hormonell wirkende Mittel". Herr K. wirkt hier recht inkohärent und unverständlich, man kann kaum folgen, weder in logischer noch in akustischer Hinsicht. Er spricht ganz undeutlich. Bei Nachfragen sagt er, "dass es sich um die relative Bildung handeln kann“. (Was meinen Sie damit?) Antwort: „Ja, die gebildeten Verhältnisse schließlich doch“.

\section{Aktivitäten, Hobbys}

Er lese keine Zeitung, Fernsehen würde er nur etwa eine viertel Stunde.

Morgens gehe er zur Arbeitstherapie nach Sehnde, mit einigen Mitpatienten fahre er im öffentlichen Bus.

Gestern sei er mit der Straßenbahn zum „Badeteich“ gefahren, er sei dann noch etwa $2 \mathrm{~km}$ zu Fuß gegangen, habe gebadet, er sei ca. 3 Stunden dort gewesen. (Hat es Ihnen Spaß gemacht?) Herr K. zuckt nervös mit den Augenlidern und sagt schließlich: „Man entspannt ja im allgemeinen".

Hobbys: (Sie malen gerne?) „Zur Zeit nicht so“. (Und außerdem?) „Jetzt gar nichts weiter“. Zur Zeit gehe er auch nicht auf den Flohmarkt.

Nach seiner Freizeit gefragt, antwortet er: „Ich habe unter einem geistigen Konflikt gelitten, durch eine Vergiftung, das waren die Giftspritzen, deshalb bin ich hier".

(Frage: Ist denn auch das Essen vergiftet?) Antwort: „Es ist schon vorgekommen, bei mir ist das vorgekommen, das Essen wurde vergiftet". Dadurch sei die "Denkfähigkeit" betroffen worden, „in Form einer chemischen Zwangsjacke“. (Frage: Wann war es das letzte Mal, dass das Essen vergiftet war?) Antwort: „Eine alte Krankenschwester hat das getan, die Schwester K., glaub’ ich“. (Frage: Wann war das?) Antwort: „Es könnten zwei Monate her sein“. (Woran haben Sie es gemerkt?) Antwort: „Das wurde mir so gesagt, außerdem fühlte man das, das fühlt man auch so“. (Woran haben Sie das gefühlt?) Antwort: „Davon schwindet mir der Kopf, dadurch bildet sich eine intensive nervliche Verfassung, außerdem hab' ich sofort an Schlaflosigkeit gelitten, an einer starken Schlaflosigkeit“. (Wer hat Ihnen das mit der Vergiftung gesagt?) Antwort: „Der Pfleger hat mich darauf hingewiesen“. (Frage: Hat der Pfleger etwas unternommen?) la, der Pfleger habe gesagt, dafür sei der nächste Vorgesetzte zuständig. Er wisse nicht genau, ob der Pfleger den auch informiert habe.

(Frage: Woran denken Sie, wenn Sie allein sind?) Antwort: „An die Zukunft vielleicht“. (Was denken Sie dann?) "Mm“, „ach so, Sie meinen, dass ich depressive Gedanken haben könne“. Er denke an Entlassung, aber da müsse erst die Entmündigung „aufgehoben“ werden. „Ich bin nicht nur vergiftet, sondern auch bestohlen und ausgeraubt worden".

(Was haben Sie im Moment für Probleme?) Herr K. seufzt, sein einziges Problem sei, „Ich leb' ja in einer psychologischen Anstalt, ich bin also nicht geistig vollwertig existent hier“. (Macht Ihnen das Sorgen?) „Sorgen, ja Sorgen, praktisch, unter der Bedingung, unter der ich hier behandelt werd', auf jeden Fall Minderwertigkeitskomplex, die psychische Einstellung mir gegenüber“. (Wer hat diese Einstellung Ihnen gegenüber?) Antwort: „Die psychologische Bildung, die Form wie ich behandelt werd' hier". (Wie gehen Sie mit diesen Schwierigkeiten um?) "Wieso soll ich mit Schwierigkeiten umgehen hier". Er glaube, dass er keine Schwierigkeiten habe. 
(Wie fühlen Sie sich körperlich?) „Etwas differiert, erkältet, wie ich schon gesagt hab“. Kopfschmerzen habe er nicht, auch keine sonstigen Schmerzen. (Haben Sie manchmal Angst?) „Nein, nein, nicht“. (Sind Sie manchmal unruhig?) „Nein, nein, nein“. (Wird Ihr Denken manchmal von irgendetwas beeinträchtigt?) „|a, durch was beeinträchtigt? Es wurde durch die Spritze beeinträchtigt“. (Wie hat sich das gezeigt?) "Nervlich störende Spritzen“.

Jetzt wird Herr K. recht unruhig und möchte nicht mehr weiter gefragt werden. Er hat auch den Verdacht, dass ich inn für "schizophrenisch“ halte und spricht wieder recht abstrus, akustisch und logisch unverständlich über Gedanken und Auffassungen, was wirklich nicht verstanden werden kann von mir. Ich frage ihn danach, was er sich wünschen würde, wenn alle Wünsche in Erfüllung gingen. Darauf sagt er nur: „Ich bin nicht abergläubisch“.

\section{Sinnwidrigkeiten}

(Dampferbild) „So was gibt es nicht - der Rauch mit der Fahne hier“.

(Pappeln) Herr K. schweigt zunächst, meint dann: „Mm, kann man nicht genau sehen, ist ... außerdem sind oben die Blätter abgefallen“.

Das Wesentliche, die verkehrten Schatten, erkennt er nicht.

\section{Epikrise}

Die bereits im Alter von 9 Jahren beginnende Psychose war anfänglich durch abstruse, uneinfühlbare Handlungsweisen, zunehmende Isolierung, aggressives Verhalten, Suizidversuche und affektive Verarmung gekennzeichnet und hatte zunächst ein überwiegend hebephrenes Muster. Im Alter von 13 lahren kamen vielgestaltige positive paranoid-halluzinatorische Symptome sowie eindrucksvolle Denk- und Sprachstörungen hinzu. Ab dem Alter von 17/18 Jahren war ein Nebeneinander von negativen und positiven Symptomen bildbeherrschend. Die Verlaufsdynamik war wechselhaft mit mehrjährigen Besserungen, welche jedoch nicht dauerhaft waren, v.a. unternahm der Patient immer wieder Suizidversuche. Seit dem Alter von 36 lahren ist der Patient dauerinstitutionalisiert und chronisch psychotisch mit multiplen paranoiden Wahnideen (Beeinflussungs-, Beeinträchtigung-, Vergiftungs-, Verfolgungs- und Bedrohungsideen). Seine Sprache ist auffallend desorganisiert, unbestimmt und floskelhaft. Es bestehen nach wie vor deutliche formale Denkstörungen mit Denkzerfahrenheit und Gedankenabbrüchen. Die Gedankengänge wirkten verschroben, waren a-logisch, weitschweifig, ungeordnet und vage. N. sprach mit sehr leiser, monotoner, wenig modulierter Stimme, teilweise flüsterte er nur. Die Bewegungen waren eckig, abgehackt, bizarr, maniriert. N. hat völlig unrealistische Zukunftsvorstellungen und lebt isoliert für sich ohne echten Kontakt zu den Mitpatienten. Außer $25 \mathrm{mg}$ Atosil benötigt er keine Medikation. Trotzdem glaubt er, er werde durch chemische Substanzen, durch „eine chemische Zwangsjacke“ in seiner Denkfähigkeit behindert und beeinflusst. Beim Abschied nach dem Gespräch entstand der Eindruck, dass N. sehr wohl emotional ansprechbar war: Er reagierte bewegt und traurig auf meine guten Wünsche für ihn.

\section{Diagnose}

Trotz jahrelang vorherrschender positiver Symptomatik mit paranoid-halluzinatorischen Symptomen und formalen Denkstörungen entspricht der Gesamtverlauf doch dem eines hebephrenen bzw. desorganisierten Typs: DSM-IV: 295.10; ICD-10: F20.10. In den letzten 10 lahren werden die paranoiden Symptome zunehmend fragmentarisch, unorganisiert und verlieren an Prägnanz, Anschaulichkeit und Schärfe. Die halluzinatorische Symptomatik tritt weitgehend zurück. Im Vordergrund steht die Desorganisation von Denken und Sprache. 


\section{Verlaufstyp}

Kontinuierlich mit prominenten negativen und später positiven Symptomen. Ausgeprägte Persönlichkeitsveränderung (Residualsyndrom, DAS-M-3: 5). In den letzten 10 lahren chronische paranoide Symptome und formale Denkstörungen.

\section{Therapie}

Im Alter von 13 Jahren 20 Insulinkomata und Fluphenazin-2 HCL-Medikation. Im Alter von 18 Jahren Elektroschocks, Pyrifer und Insulin. Später Behandlung mit verschiedenen Neuroleptika.

\subsubsection{1b}

Nachbeobachtungszeit: 44 Jahre

Familienanamnese:

Schwester des Vaters geistig behindert.

Großmutter väterlicherseits drohte mehrmals mit Selbstmord.

2 Cousinen der Mutter schizophren.

Familienmilieu

Vater erfolgreicher Kaufmann, von der Mutter bei Nachuntersuchung des Patienten als sehr empfindsam, feinfühlend, hochgeistig und musikalisch geschildert.

Mutter ebenfalls sehr geistreich, redegewandt und temperamentvoll, feinsinnig, aber kühl, etwas überspannt. Sie ist eine polnische Jüdin, deren Geschwister alle im 3. Reich umgekommen sind! Sie ging nach dem Krieg deshalb nach Amerika, heiratete dort einen Professor, von dem sie sich „im gegenseitigen Einvernehmen“ wieder scheiden lies. Auch die 2. Ehe mit dem leiblichen Vater des Patienten wurde z. Zeitpunkt des Erkrankungsbeginns geschieden.

Eigenanamnese: unauffällig

\section{Prämorbid}

Gut begabt (Gymnasiast), kontaktfähig; viele geistige Interessen, jedoch sehr ichbezogen, sehr sensibel, introvertiert, ich-schwach, lässt sich leicht unterkriegen, Einzelgänger.

Beginn: 14 Jahre, knickhaft

\section{Psychopathologisches Bild}

Zunehmend Schulschwierigkeiten, Konzentrationsstörungen, Interesseverlust, Minderwertigkeitsideen, Kontaktschwierigkeiten. Der Junge unternahm wiederholt Suizidversuche. Er wurde zunehmend aggressiv, insbesondere gegen die Mutter, die er einmal mit dem Messer bedrohte. Er legte Feuer, schlief schlecht, war sprunghaft in seinen Gedanken, unstet im Handeln, redete viel und unzusammenhängend, äußerte Verfolgungsideen, hatte nachts Visionen von Einbrechern und war sehr misstrauisch. Immer wieder geriet er in Erregungszustände, zeitweise zeigte er ein substuporöses Verhalten. Er behauptete plötzlich, ein Idiot zu sein, nicht mehr denken, schreiben und lesen zu können; er verweigerte die Nahrung, äußerte, sich nicht mehr so freuen zu können wie früher. 
Mit 15 Jahren litt er unter Zwangsvorstellungen, wurde zunehmend ungezogen, rücksichtslos und ungehemmt. Während der Klinikbeobachtung 1 Jahr später war er salopp, unbekümmert, nonchalant, zeitweise ausgesprochen läppisch, affektiv flach, litt unter hypochondrischen Beschwerden, zeigte keinerlei Bindung an irgendeinen Menschen. Stereotyp stellte er immer wieder dieselben Fragen („gibt es das, dass kräftige Männer ohne Bewegung dick werden?", „schwitzt man viel, wenn man kräftig ist?" „Muss man sich jeden Tag das Genitale waschen?"). Zeitweise war er gespannt, aggressiv, flegelhaft. Nach der Entlassung aus stationärer Behandlung ( 5 Monate Dauer) arbeitete er zunächst als Hilfsarbeiter zu Hause in der väterlichen Fabrik. Nach einigen Wochen kam es wieder zur Verschlechterung, er äußere Selbstmordabsichten und unternahm einen Suizidversuch. Anschließend war er läppisch, euphorisch, gespannt, negativistisch, äußerte Beziehungs-, Selbstbeschuldigungs- und Nichtigkeitsideen und wollte wiederholt Suizid begehen.

Therapie: 20 ES, 30 Insulinkomata

\section{Nachuntersuchung 15 Jahre nach Erkrankungsbeginn, Alter des Patienten 29 Jahre}

Die katamnestischen Daten wurden aus Gesprächen mit dem Patienten, seiner Schwester und seiner Mutter gewonnen und später aus Briefen der Schwester und durch Epikrisen der behandelnden Krankenhäuser ergänzt.

Nach der Entlassung hat der Patient zunächst eine 3-jährige kaufmännische Lehre im Eisenwarenhandel durchgemacht und anschließend 1 Jahr die Eisenwarenfachschule besucht. Danach war er im Unternehmen seines Vaters (Eisenwarengroßhandel) beschäftigt. Dort gab es jedoch Schwierigkeiten wegen Misstrauens und starker Selbstüberschätzung seitens des Patienten, es erfolgte deshalb ein Wechsel zu einem anderen Unternehmen derselben Branche. 10 Jahre nach Beginn der Erkrankung war der Patient eine Zeitlang stärker psychotisch: er litt unter der Vorstellung, an einer zerstörenden Krankheit zu leiden und sammelte Zeitungsausschnitte als Beweise hierfür, er glaubte, seine Kollegen anzustecken, er war völlig unkorrigierbar und unbelehrbar, auch nicht durch ärztliche Untersuchungsergebnisse. Er kapselte sich immer mehr ab, schließlich war er überzeugt, von seiner Krankheit innerhalb von spätestens 2 Wochen „zerstört“ zu werden. Nach einigen Wochen sprach er nicht mehr davon, behauptete aber in den nächsten 3-4 lahren, dass er schlechten Geruch verbreite, deshalb kaufe man auch nicht bei ihm und er müsse so versagen. Es tropfe dauernd bei ihm aus der Harnblase, der Patient trug deshalb eine komplizierte Auffangvorrichtung. Eine Zeitlang glaube er auch, geschlechtskrank zu sein.

Im Alter von 29 lahren, bei der Nachuntersuchung, gab er an, dass er häufig unter traurigen Verstimmungen leide, ,ich komme manchmal an den Rand, in eine seelische Lage, wo ich aufpassen muss, wo ich die Beherrschung verliere, ich komme dann in eine Art Dämmerzustand, wo ich nicht mehr klar denken kann“; er glaube dann, er sei "bescheuert" und er habe die Gewissheit, es lohne sich nicht weiterzuleben; er habe dann Selbstmordabsichten und leide unter starken Angstzuständen. Er kenne das Gefühl der "Weltuntergangsstimmung“ und der „völligen Ratlosigkeit“. Überhaupt sei er immer „Einzelgänger" gewesen und habe sich immer einsam gefühlt, er habe sich wiederholt in einem „Circulus vitiosus“ gefunden. $Z u$ anderen Menschen könne er keine innigen und herzlichen Gefühle hegen. Auf die Frage, ob er darüber traurig sei, antworte er: „Das ist der Grund meiner Nervenkrankheit“. Und weiter: „Wenn ich die Möglichkeit habe, meinen Gesellschaftstrieb zu befriedigen, entsteht in mir das Gefühl der seelischen Leere, man könnte ganz irre darüber werden; man empfindet einen Mangel“. 
Der Gedankengang war sprunghaft, glitt von einem Thema zum anderen, es wurden Dinge miteinander verknüpft, die nicht zueinander gehörten. Über sich sagt der Patient, dass er ein gespaltener Mensch sei, „ich weiß, dass mein Ich gespalten ist“. Die Spaltung bestehe in "apollinisch und dionysisch", zwischen „Tiefe und Oberflächlichkeit“. Diese „Gespaltenheit" bestehe insbesondere in erotischer Hinsicht, mehr wolle er darüber nicht sagen. Oft klang in seinen Sätzen ein leeres, fades Pathos an; der Sprachstil war nicht selten geschraubt, maniriert, nichtssagend, und doch auch wiederum war echtes Unbehagen spürbar, vielleicht sogar inneres Leiden an sich selbst, ein Empfinden von dem, was inm versagt ist durch das Resultat seiner Erkrankung. So war viel Widersprüchliches und Sich-Widerstreitendes in seinem Wesen, das Verhältnis zur Mitwelt, zur Freundin oder zur Mutter äußerst ambivalent. In seiner Zuwendung zeigte er sich sprunghaft wechselnd, mal anhänglich, mal abweisend und plötzlich patzig und dann gleich wieder liebevoll und freundlich. Sein Verhalten Fremden gegenüber schien zwischen misstrauisch-scheuer Zurückhaltung und aufdringlicher Distanzlosigkeit zu wechseln. Im Umgang mit Mitmenschen zeigte er mangelndes Geschick und Einfühlungsvermögen und neigte zu teilweise erheblichen Taktlosigkeiten. Hemmungslos berichtete er von den intimsten Dingen. Andererseits gebrauchte er im Gespräch häufig nichtssagende Phrasen und Allgemeinplätze. Oft widersprach er sich: während er eben noch von traurigen Verstimmungen und Minderwertigkeitsideen sprach, betonte er gleich darauf, dass er dem Leben und der Welt positiv gegenüberstehe. Er denke viel über sich selbst nach, beobachte und kontrolliere sich selbst viel und sei öfter mit sich unzufrieden. Er sei leicht erregbar und aufwühlbar, seine Stimmung schwanke leicht, er leide unter Konzentrationsschwäche und gerate "leicht aus dem seelischen Gleichgewicht" und sei dann verstimmt oder aufgeregt. Der „schönste Moment“ im Leben sei die Musik. Der Patient ist Bratscher und spielt im Orchester und im Quartett. Im Gespräch wechselte der Patient dauernd und abrupt die Themen, zwischendurch stellte er ähnliche läppische, hypochondrische Fragen wie zur Zeit des Klinikaufenthaltes (wie er am besten alt werden könne, durch welche Präparate oder Speisen er kräftig werden könne, welche Bücher und Schriften er sich kaufen müsse, um zu erfahren, ob man „das Leben des Menschen auf etwa 100 lahre verlängern und im Jahre 2050 um etwa 50 Jahre verlängern“ könne. Gelegentlich äußerte er völlig abstruse und aus der Luft gegriffene Ziel- und Wunschvorstellungen, z.B. dass er nach Amerika auswandern wolle ohne zu wissen, was er dort tun möchte.

\section{Katamnese}

4 lahre nach der 1. Nachuntersuchung im Alter von 32 Jahren schloss der Patient sein Musikstudium in der außergewöhnlich kurzen Zeit von 2 Jahren mit einem Diplom als Orchestermusiker (Bratscher) ab. Ein halbes Jahr danach unternahm er einen Suizidversuch (Schlafmittel), bei dem er sich eine Schädelfraktur mit einer schweren Commotio zuzog. In den letzten Monaten davor war der Patient häufig umtriebig-unruhig, geriet in tätliche Auseinandersetzungen mit Freundinnen und Nachbarn, die ihn teilweise schroff ablehnten und deren Zuneigung bzw. Respektierung er erzwingen wollte. Er litt unter Konzentrationsschwäche und Schlaflosigkeit. Nach Abklingen der Folgeerscheinungen der schweren Commotio kam es zu einer weitgehenden Besserung der Konzentrations-, Antriebs- und Kontaktstörungen (Therapie: Dapotum). Inzwischen hat der Patient die Stelle eines Bratschers in einem bekannten Städtischen Orchester angenommen und auch bereits zahlreiche Konzerte gegeben.

\section{Epikrise}

Briefe des Patienten spiegelten das breite Spektrum vielfältiger, wunderlicher, verschrobener und fremdartig erscheinender Wesensauffälligkeiten sowie die facettenreichen - oft 
nur diskreten - Störungen und Hemmungen des Patienten im affektiv-emotionalen Bereich wider, wie sie für den schizophrenen Sonderling typisch sind. Sie sind in diesem Fall charakteristisch, auch in ihrer oft rührenden Naivität.

Für den Außenstehenden und für einen Menschen ohne psychopathologische Kenntnisse sind diese an sich typischen Wesenszüge in ihrer Genese völlig unverständlich, was wiederum zu ernsten Problemen und Konflikten mit der Umwelt führen kann. Ihnen ist gerade ein in seiner Seinsmöglichkeit beschränkter Mensch mit einer psychosebedingten umgewandelten Persönlichkeitsstruktur und zusätzlich bestehenden Defizienzsymptomen nicht immer gewachsen, Fehlreaktionen und -haltungen sind die Folge und können neue Schübe bzw. Rezidive vortäuschen, die in Wirklichkeit keine sind. Die letzte Episode mit dem Suizidversuch ist sicherlich zumindest auch stark reaktiv mitbedingt gewesen.

\section{Weitere Katamnese}

Im Jahr 1973, im Alter von 35 Jahren, hat der Patient mich in Heidelberg aufgesucht. Er litt unter der Idee, geschlechtskrank zu sein und war in seinem Gedankengang unlogisch, sprunghaft, verschroben. Er beschäftigte sich mit dem Thema "Weltuntergang" und „)enseits" sowie mit Konflikt- und Friedensforschung. Über dieses Thema schrieb er ein Buch, was er an mehrere Verlage verschickt hatte, ohne dass es angenommen wurde. In einem Brief schrieb er wörtlich: „Wenn ich aber der Menschheit gedient haben würde, wenn ich die Möglichkeiten zu einem friedlichen Leben geschaffen haben würde, wenn ich Möglichkeiten geschaffen haben würde, um die abendländische Kultur vor dem mit Sicherheit anzunehmenden Untergang zu retten, dann hätte ich am Lebensende möglicherweise das Gefühl, das meist Mögliche aus meinem Leben gemacht zu haben. Mein Leben ist nur wertvoll, wenn es für andere Menschen wertvoll ist!!!"

Im Alter von 41 Jahren kam es zu einer Exazerbation der paranoiden Symptomatik: J. war zu Verwandten geflüchtet, weil er sich vom Geheimdienst verfolgt glaubte. Er meinte, dass er seit 2 lahren vom Geheimdienst verfolgt werde und dass er sich deswegen „hier in Schutzhaft" begebe, da er keinen anderen Ausweg mehr sehe. Drei verschiedene Geheimdienste und Truppenteile seien hinter ihm her, um ihn zu entführen. Als Grund dafür gab er an, dass er an einer "neuen Infektionskrankheit“ leide. Es sei zwar sehr schwer, dies nachzuweisen, die Erkrankung sei aber äußerst ansteckend, und er habe bereits „sehr viele Menschen damit infiziert". Es sei eine Geschlechtskrankheit, und er habe deswegen Briefe an amerikanische Spezialinstitute für Allergologie und Infektionskrankheiten geschickt sowie an eine Ärztegemeinschaft in Frankfurt und auf die bei ihm bestehende gefährliche Erkrankung hingewiesen. Durch diese Briefe sei inm der Geheimdienst irgendwie auf die Spur gekommen, seitdem werde er von ihm gejagt. Er habe jedoch kein Geständnis abgegeben und werde jetzt „,von den Verfolgungen so zermürbt, dass dies inzwischen erfolgt ist“. Ein Drittel bis zur Hälfte der deutschen Bevölkerung sei inzwischen infiziert, die Ärzte wüssten das nur nicht.

Wenig später schrieb er an das Gesundheitsministerium in Bonn und an die Staatsanwaltschaft ein „Geständnis“. Die ausbleibende Antwort erklärte er damit, dass die Sache geheimgehalten werden müsse, um eine Panik unter den Menschen zu vermeiden. Jetzt versuche man ihn, ohne großes Aufsehen zu entführen und unschädlich zu machen. Seit 2 Jahren seien schon mehrere Entführungsversuche unternommen worden, einmal sogar mit einem Hubschrauber. Auch sei er bei einem Konzert von 2 Leuten in ein Gespräch gezogen worden, nur um ihn dann zu entführen. In den letzten Wochen habe man sogar versucht, unter seinem Haus einen Tunnel zu bauen, um dies in die Luft zu sprengen. Er habe ständig nachts Geräusche gehört. 
Der Patient hatte ein ausgeprägtes Wahnsystem mit Beobachtungs-, Beziehungs- und Verfolgungsideen entwickelt. Deshalb stationäre Behandlung mit hochpotenten Neuroleptika, Dauer 6 Monate. Danach ist der Patient wieder kontaktfähiger, antriebsreicher, spielt wieder Bratsche, die Wahnideen sind in den Hintergrund getreten. Nach wie vor jedoch trägt der Patient einen Urinfänger. Er glaubte, bald sterben zu müssen und an einer chronischen Blasenreizung mit Blasenschrumpfung erkrankt zu sein, die bald zu einem „Harnröhrenverschluss" führen würde.

\section{Nachuntersuchung, 44 Jahre nach Erkrankungsbeginn, Alter des Patienten: 57 lahre}

Die Untersuchung findet in der Wohnung des Patienten (J.) statt. Es ist eine Zweizimmerwohnung, die einen so ungepflegten Eindruck macht, dass man schon von verwahrlost sprechen muss. Die Küche steht voll mit völlig verdrecktem Geschirr. Das Küchenzeug bzw. Geschirr ist zusammengeflickt. Es scheint seit Wochen bzw. Monaten nicht mehr gewaschen bzw. gespült worden zu sein. J. schläft in einem schmalen Gang, zur Küche gehörend, auf einer Schaumgummimatratze, die schon verschimmelt ist, sie wirkt wie vom Müll abgeholt. Mit einem Bindfaden hat er an das Holzgestell eine Tasse gebunden. Der Verschlussdeckel des Gucklochs in der Tür ist mit Stoff umwickelt, so auch viele Gegenstände in der Küche und sein recht skurril aussehender Bleistift. Auf Nachfrage gibt er an, dass er dies wegen seines „Rheumatismus" tue. - I. leidet nicht an Rheumatismus, sondern bildet sich dies nur ein, er hat sich auch nicht diesbezüglich untersuchen lassen. Er ist von dieser Wahnidee auch nicht abzubringen. Das "Schlafzimmer" ist vollgestellt mit Wäscheständern und anderen Utensilien. An den Wänden hängen Kinderzeichnungen und drei recht verdreckte grünliche Anoraks. Die Jalousien sind heruntergelassen - später ist zu erfahren, aus Angst davor, durch das Fenster fotografiert bzw. beobachtet zu werden.

I. hat mich noch im Taxi wiedererkannt, er schob einen kleinen Wagen mit sehr schmutzigen schweren Taschen vor sich her, so eine zweirädrige Schubkarre, wie sie ältere Frauen zum Einkaufen benutzen. Er schleppt die Sachen nach oben. J. trägt ein breites Kopf-Haar-Band, wie es Skispringer benutzen. Sein pechschwarzes Haar ist mittellang und reicht bis zur Höhe des Unterkiefers. Er hat einen Bart. Die Kleidung ist sehr nachlässig, sehr ungepflegt, übelriechend. J. wirkt wie ein russischer Mönch bzw. Einsiedler aus dem Zarenreich - so könnte Rasputin ausgesehen haben, nur war der natürlich gepflegter.

I. berichtet sofort, dass er "von Dämonen besessen“ sei. Das habe er bei der letzten Begegnung mit mir 1973 in Heidelberg noch nicht gewusst. Er möchte mit mir über den „Vorgang der Befreiung “sprechen. Es gebe keinen anderen Weg, „als über Jesus Christus“. Es bedürfe einer bewussten Entscheidung über Jesus Christus, nämlich sein Leben mit Christus in Ordnung zu bringen, um sich von seinen eigenen Sünden „und von den Sünden der Vorfahren zu befreien". Seit den 70er Jahren habe er Kontakte mit einem Baptisten-Pastor und mit Befreiungsdiensten aufgenommen, seit 1985 sei er von einem Teil der Dämonen befreit, seit 1986 sei er von allen Dämonen befreit. J. meint, er habe 1974/75 in Hilchenbach - dort spielte er damals im Orchester - damit begonnen, „Befreiungsdienste in Anspruch zu nehmen“. Er habe Fratzen gesehen, die hätten ihn nachts "in den Hintern gestochen“, das sei sehr schmerzhaft gewesen. Er sei dann davon aufgewacht. Wörtlich sagt I.: „Wenn ich Gott lästere, kehren die Dämonen zurück“. „Ich stelle alle Menschen unter das verflossene Blut Christi“. (Was meinen Sie damit?) Antwort: „Deshalb, weil, wenn die Dämonen von einem ausfahren sie in einen anderen reinfahren können, deshalb binde ich die Dämonen im Namen Christi“.

„Ich bin froh, dass ich Vermittler für die Menschen sein darf, ich will mich vor Gott demütigen". 
Es sind 27 Dämonen, die in ihm sind bzw. waren. „Ich befehle euch im Namen Jesu Christi von mir auszufahren“. „Ich zähle die alle einzeln auf, ich habe gelernt, sie zu bezeichnen“. „Im Namen Jesu Christi befehl ich dir, deinen Namen zu sagen“, „dann nennen die ihren Namen“. (Hören Sie den Namen dann?) Antwort: „Nein, ich seh die vor meinem geistigen Auge“. Der Dämon könne dann nicht mehr anders und nenne seinen Namen, wenn er dies im Namen Christi gefordert habe. Und I. fährt unvermittelt fort: „Satan, im Namen Christi sage ich mich los von dem Dämon so und so". Er müsse den Dämon auch manchmal umschreiben, die Befreiung sei eine „geistige Gratwanderung“. Er dürfe nichts Schlechtes denken, keine bösen Gedanken haben, nicht fluchen. Das sei ein „schlimmes Zwangsgefühl“. „Wenn der Dämon zurückkehrt, dann kommt eine innere Unruhe und Getriebenheitsgefühl über mich wie ein Mensch, der eine Zwangsneurose hat“.

„Man muss sich eine Vergebungsliste anfertigen für jede Verletzung, die man in der Kindheit erfahren hat“. „Allen Menschen, die mir in der Kindheit Verletzungen zugefügt haben, habe ich mit dieser Vergebungsliste vergeben“.

J. lässt sich überhaupt nicht von seinen Gedankengängen ablenken bzw. lässt sich nicht unterbrechen. Meine Fragen solle ich erst nach „Erarbeitung des Gedankenschemas“ stellen. Auch fragt I. immer wieder, ob ich meine Blätter auch nummeriert hätte. Das sei wichtig, damit ich auch alles richtig wiederfinden und in einen richtigen Zusammenhang stellen könne.

I. berichtet, er sei Mitglied einer „Charismatischen Gemeinde“. „Taufe mit dem Heiligen Geist, der Geist spricht in mir". I. spricht dann einen Spruch in einer auch für ihn unverständlichen Sprache, klingt wie ein Gemisch aus Russisch-Katalanisch und Südfranzösisch. Er fährt dann fort und sagt, „ich muss jede Botschaft sorgfältig prüfen, ob sie auch von Gott kommt“. Er könne auch vom Teufel verführt werden oder "vom eigenen adamitischen Selbst“. Auf Nachfrage meint er damit, dass er auch von der Natur Adams, die sündig und von Gott getrennt sei, verführt werden könne.

Auf meine Frage, ob er die Stimme Gottes höre, meint er: „Die Stimme Gottes sehe ich vor dem geistigen Auge“, er höre sie nicht. Es sei besser, von den Dämonen nicht zu sprechen, sonst würde es für ihn „gefährlich“, das sei „zuviel Ehre dem Teufel angetan“.

I. liest die Bibel, geistliche Bücher, auch die Tageszeitung. „Jesus möchte, dass ich Vieles nicht mehr lese, z.B. den Sportteil. Darin wird nur über die Götzen geredet". I. meint damit die sportlichen Helden. „Das hängt mit meinem Minderwertigkeitsgefühl zusammen, damit, dass ich eine Trichterbrust habe und körperlich schmächtig bin“. Und er fährt fort: „Ich habe einen Geniedämon“. Er spricht vom „erlösenden Wunderkind“, das sei seine Rolle gewesen. „Meine Mutter hat mich in diese Rolle reingezwängt, als ich 12 Jahre alt war“. Die Mutter sei mit ihm, seiner Schwester und seinem Vater in die USA ausgewandert. Die Mutter habe mit ihm geprahlt: „Mein Sohn ist ja so musikalisch und der ist sooo sprachbegabt“. „In dem Moment ist der Größenwahndämon in mich eingefahren“. - Später im Gespräch mit dem Bruder von J. wird in der Tat deutlich, dass die leibliche Mutter von J. sehr mit inm geprahlt hat in den USA, dass I. „das Prahlkind gewesen“ sei, dass die Mutter sich mit ihm geschmückt habe. Sehr traumatisch sei gewesen, dass der Vater plötzlich wieder nach Europa zurückging und der älteren Schwester T. aufgetragen hatte, I. zu sagen, dass er nun allein mit der Mutter zurückbleiben müsse. T. ging zum Studium nach Europa zurück.

Erstaunlich ist J's Schilderung der Mutter: „Meine Mutter wollte Liebe und Zärtlichkeit von mir haben, dass konnte ich ihr nicht geben, das war mir lästig, sie war sehr geltungssüchtig, sie hat mir erzählt, dass sie von ihrer Mutter abgelehnt worden sei und dass ihre Zärtlich- 
keitswünsche zurückgewiesen worden seien“. „Deshalb ist sie so geltungssüchtig geworden, eine Salonlöwin“. Diese Schilderung wird auch von l's Halbbruder bestätigt.

I. fährt dann fort, über sein verzweigtes Wahngebäude zu berichten, welches sich um den Geheimdienst dreht, von dem er verfolgt werde, in seiner Stadt sind sogar Aufklärungsflugzeuge AVACS auf ihn angesetzt, auch habe der damalige Bundeskanzler "Spione auf mich angesetzt“. Er werde „mit den raffiniertesten Methoden der Elektronik gejagt“. Seine Heizung mache er nicht an, er benutze sie nicht, „weil die Geheimdienste da hineinbohren, um mich zu fangen“. Spontan meint er, er leide „vermutlich an Verfolgungswahn“. Er nehme aber keine Medikamente und brauche auch keinen Hausarzt. Psychisch gehe es inm „,hervorragend, einfach deshalb, weil ich gehorsam bin und alle Sünden bekenne“.

Im übrigen besteht eine bemerkenswerte Konstanz der jetzigen mit der damaligen Symptomatik, die er als 14-jähriger Junge geboten hatte, nämlich einen schwächlichen, unkräftigen Körper zu haben und von allen möglichen Krankheiten heimgesucht zu werden. In den letzten Jahren ist er überzeugt, an Rheumatismus zu leiden, weshalb er auch dieses Kopfband trage („Ich habe mit Rheumatismus zu tun, ich habe ein Kältegefühl an den Ohren, das dämpft das Kältegefühl"). - Es ist Hochsommer!

Auf meine entsprechende Frage gibt er an, dass er körperlich sehr viele Beschwerden habe. Er habe im Keller im kalten Raum Flöte geübt und habe sich dabei „den Rheumatismus geholt“. Er habe ein „Kältegefühl in manchen Gelenken“. - Hier erinnert I. an Christian Buddenbrock.

Als |. über die Mutter seiner Schwägerin sprich, kreiert er einen Neologismus: So sei bei ihr eine „Sündenbockgeschlechts-rollenprogrammierung" erfolgt, sie hätte eigentlich ein Sohn sein sollen und sei deshalb ein „Mannweib“ geworden.

Die hypochondrische Thematik seines Wahns besteht in wechselnder Intensität und Akuität immer noch (von Krankheitsbeginn an). So berichtet J. spontan davon, dass „die Herpes Simplex II-Krankheit“ durch ihn entstanden sei. Er habe dieses Unrecht, das durch ihn entstanden sei, durch Informationen, die er an das National Institute of Allergology and Infection Diseases weitergegeben habe, „gesühnt“. Der Herpes Simplex II-Virus greife die Geschlechtsorgane an, die Prostata, auch den Hoden, „da entstehen Knoten, das Virus steigt die Wirbelsäule hoch bis ins Gehirn rein“. Im übrigen glaubt er, dass der Geheimdienst seine Nahrung „mit Krebszellen bestrichen“ habe, seitdem habe er Dickdarm- und Prostatakrebs. (Frage: Wie zeigt sich das?) Antwort: „Ich habe oft Schmerzen, und das, was abgeht beim Stuhlgang zeigt manchmal so Einbuchtungen, da muss eine Schwellung sein im Dickdarm und manchmal kommt das, was abgeht, in Etappen und nicht direkt hintereinander".

I. schleppt seine beiden Taschen, die prall gefüllt sich mit allem möglichen Sammelsurium, überall mit hin, aus Angst, sie würden in seiner Abwesenheit „vom Geheimdienst bestrahlt“.

Auf die Frage, ob er eine Lebensmaxime habe, antwortete er: „Das Himmelreich erreichen, wenn ich könnte, würde ich als Erweckungspriester arbeiten. Aber Jesus versperrt mir den Weg dazu“. (Frage: Was meinen Sie damit?) Antwort: „Weil die Geheimdienste, auch die Polizei, mich festnehmen wollen, ohne Zeugen, lebendig oder tot".

\section{Epikrise}

Die schleichend beginnende und chronisch verlaufende Psychose weist eine erstaunliche Konstanz der Symptomatik auf, v.a. der recht skurrilen Wahninhalte, die immer obstrusere Formen annehmen, zunehmend bedrängender werden und die totale Herrschaft über Denken und Handeln des Patienten gewonnen haben. Anfänglich war die Verlaufsdynamik noch 
wechselhaft mit Zeiten anhaltender Besserung. Seit 20 lahren ist der Patient jedoch berentet und nicht mehr arbeitsfähig, spielt gelegentlich nur noch auf der Flöte. Ein Leidensdruck besteht erstaunlicherweise nicht, der gravierenden Verwahrlosung steht der Patient gleichmütig gegenüber, „psychisch“ gehe es ihm "hervorragend“.

\section{Gesamtdiagnose}

Schizophrenie, paranoider Typ (F20.0, 295.30). Schizophrenes Residuum (F20.5, 295.60). Schlechte soziale Anpassung (DAS-M-3: 4).

\subsubsection{C}

Nachbeobachtungszeit: 30 Jahre

\section{Familienanamnese}

Der Vater des Pat. sowie der Großvater väterlicherseits sind beide an den Folgen einer Chorea Huntington verstorben. Die Großmutter väterlicherseits litt an einer schizophrenen Psychose.

Milieu: Bescheidene Verhältnisse, stark christlich geprägt.

Psychomotorische Entwicklung: unauffällig

Prämorbid: Einzelgänger, sehr guter Schüler. IQ 143/104 (Gesamt-IQ 128)

Erkrankungsalter: 9 Jahre

Beginntyp: schleichend

\section{Symptomatologie}

Im Alter von 9 Jahren trat eine allmähliche Wesensänderung ein: Der Junge isolierte sich zunehmend und fühlte sich von seinen Mitschülern verlacht, gehänselt und abgelehnt. Deshalb Vorstellung in einer Beratungsstelle. Im Alter von $11 \frac{1}{2}$ Jahren kamen starke Angstgefühle hinzu, vor allem paranoide Ängste, Verfolgungsideen, Selbstmorddrohungen, Schulverweigerung, zunehmende Aggressivität, der Junge wurde depressiv-negativistisch, misstrauisch, zog sich immer mehr zurück und war antriebsarm. Dauer dieses Zustandsbildes: 1 Jahr. Während einer 8-wöchigen stationären Behandlung mit Elektroschocks und Neuroleptika. 4 Wochen später kam es wiederum zu einer Verschlechterung mit zunehmender Widersetzlichkeit, Aggressivität, Selbstzweifel, Rückzugstendenzen und Misstrauen. Deshalb erneute stationäre Behandlung von 4 Monaten Dauer. Danach deutliche Besserung, der Junge war kontaktfähig, ging wieder zur Schule (Gymnasium).

Nach einem halben Jahr, im Alter von 13 Jahren, wurde er wieder vermehrt aggressiv, es kam zu tätlichen Auseinandersetzungen mit seiner Mutter und dem jüngeren Bruder sowie der Großmutter. U.a. hat er die Mutter mit dem Messer bedroht. Deshalb war erneut eine stationäre Behandlung notwendig (Dauer: 6 Monate). Der Patient war hochgradig erregt, handgreiflich, sprach nur mit leiser Stimme, umständlich, weitschweifig. Seine Mimik war starr, er zeigte keinerlei affektives Mitschwingen. Der Junge wird als sehr misstrauisch, depressiv und negativistisch geschildert.

In der Folgezeit besteht vorwiegend eine negative Symptomatik mit Rückzug, Adynamie, Initiativelosigkeit bis zur völligen Handlungsunfähigkeit, auch bei einfachen täglichen Verrichtungen immer wieder stärker ausgeprägte paranoide Tendenzen mit extremem Misstrauen 
und Beziehungsideen. Deshalb immer wieder stationäre Aufenthalte von 6-7 Monaten Dauer notwendig. Zwischendurch Gymnasialbesuch, der mit dem Abitur abgeschlossen wird. Im Alter von 26 Jahren zunehmend verschrobene Verhaltensweisen, er stapelt Kot in seinem Zimmer und fühlt sich verfolgt.

Im Alter von 30 Jahren traten positive Symptome in Form von optischen und akustischen Halluzinationen und paranoiden Beziehungs- und Verfolgungsideen in den Vordergrund, außerdem Zwangshandlungen in Form von Zwangsritualen und immer wieder auftretende katatone Erregungszustände. Eine CT-Untersuchung ergab diskrete atrophische kortikale Veränderungen frontal und parietal mit geringer Erweiterung der äußeren Liquorräume. MRTBefund o.B., insbesondere keine Veränderungen, die für eine Chorea Huntington sprechen.

Im Alter von 32 Jahren starke psychotische Aktivität mit Verfolgungsideen, akustischen Halluzinationen, Stimmen, die ihn beschimpfen, formale Denkstörungen (Gedankenabreißen, Gedankensprünge, Neologismen), Verfolgungsideen, Beeinflussungswahn, Bedrohtheitsideen (befürchtet, ermordet zu werden, nach vorausgegangener Folterung). Er fühlte sich einem „Mordkomplott ausgesetzt“ und glaubte u.a., er solle verschleppt, ermordet und von Ärzten durch eine Genmanipulation zu einem „Mongoloiden umgewandelt und zurechtgeschneidert" werden. Immer wieder wird er von starken Ängsten überflutet und bittet flehentlich um Rettung vor dem Mordkomplott. Zusätzlich imperative akustische Halluzinationen, Stimmen, die zum Selbstmord aufrufen. Die Psychose ist Neuroleptika-resistent. Die psychotische Phase hält insgesamt 7 Jahre an! Danach wurde eine tagesklinische Behandlung möglich, allerdings ist der Pat. chronisch-psychotisch und gerät immer wieder in kataleptische Zustände. Einmal hatte er die Station verlassen, fuhr mit dem Zug nach Genf, auf der Rückfahrt wurde er in der Heidelberger Innenstadt nackt und in einem verwirrten Zustand aufgegriffen.

\section{Nachuntersuchung im Alter von 39 Jahren, 30 Jahre nach Erkrankungsbeginn}

Der Patient wohnt inzwischen in einem betreuten Wohnheim für psychisch Kranke. Er hat einen sehr differenzierten, intelligenten Gesichtsausdruck. Die Mimik ist jedoch auffallend starr, sehr modulationsarm. Die Sprache ist langsam, gedehnt, dysarthrisch. Er hat eine ausgeprägte oro-bucco-faciale Dyspraxie. Der Patient zeigte andauernde, stetig wiederkehrende Stereotypien, so fasste er sich fortwährend mit den Fingerspitzen der rechten Hand an die Nase. Sein Gang ist großschrittig, maniriert, gestelzt, andeutungsweise Storchengang! Der Oberkörper ist dabei steif und nach hinten gebeugt, mit den Armen macht er rudernde Bewegungen.

Er schaut mich unverwandt ernst an. Wenn er mal lacht, verzerrt sich das Gesicht zu einer Grimasse.

Der Patient berichtete, dass er 10 lahre lang in einem Wohnheim gelebt habe, er habe damals "nur Reisen“ gemacht. Er sei jeweils allein gereist, das Geld habe er von seiner alten Tante bekommen. Die Reisen habe er selbst organisiert. U.a. sei er eine Woche in Florenz gewesen, eine Woche in Rom, 14 Tage in Paris, in der Toskana, in Frankreich etc. Im „Großraum Paris“ sei er mehrmals gewesen. Eigentlich habe er Latein, Griechisch und Kunstgeschichte studieren wollen, habe aber lieber Reisen unternommen. Das Reisen sei sein Hobby. 5 Wochen vor der Nachuntersuchung sei er in die Schweiz aufgebrochen, sei aber in Karlsruhe „hängen geblieben“. Er habe im Zug getobt, „ich habe wieder die Stimme gehört, die begleitet mich ständig“.

In diesem Zusammenhang berichtet der Patient über imperative akustische Halluzinationen, die Stimme erteile ihm Befehle und peinige inn sehr. Außerdem äußerte er Bedrohtheits- 
ideen, Angstgefühle, die Stimmen würden ihn bedrohen. Im Übrigen ist der Patient autistisch-zurückgezogen, einzelgängerisch, introvertiert, sonderlingshaft, affektiv verflacht und antriebsarm. Seine Antworten sind teilweise sehr verschroben, alogisch, konkretistisch, er ist zwanghaft prinzipienbezogen.

Der Patient berichtet, dass er ab und zu die Zeitung lese, die er sich am Kiosk kaufe, regelmäßig lese er den „Spiegel“. Er interessiere sich sehr für Politik.

Regelmäßig arbeite er in der Kochgruppe mit, dort fühle er sich wohl, im Übrigen gehe er gern spazieren. Ansonsten höre er gerne klassische Musik. Eine regelmäßige Tätigkeit könne er nicht mehr ausüben. Gelegentlich gehe er mit Mitbewohnern des Wohnheims in eine Eisdiele oder in ein Café, trinke dort Kaffee. Außerdem sammle er Briefmarken.

Er habe weder körperliche Beschwerden noch Sorgen. Nach seinen Zukunftsvorstellungen befragt, meint er: „Wenn ich hier im Wohnheim bleiben kann, kann ich zufrieden sein. Besser wäre es natürlich, ich wäre in einem Haus, das mehr im Grünen läge“. Nach seinem Lieblingswunsch gefragt antwortet er: „dass ich nicht nochmal hierher brauche und draußen leben könnte".

Befragt, ob er besondere Eigenschaften habe, meint er: „Mein starkes politisches Interesse und mein erstklassiges Gedächtnis". (Frage: Woran denken Sie, wenn Sie alleine sind?) Antwort: „An nichts Besonderes“. (Frage: Was denken Sie über das Leben?) Antwort: „Trotz meiner Krankheit bin ich doch eher geschont worden, ich habe nie körperlich arbeiten müssen“. Über die Frage, was ihm am meisten Sorge bereite, habe er noch nicht nachgedacht. Auch habe er keine besondere Lebensmaxime, "nach der bin ich noch auf der Suche. Die Anpassung hier ist oft ein Kampf". (Frage: Zu wem haben Sie eine besonders enge Beziehung?) Antwort: „Das könnt ich nicht sagen“. Er habe zu niemandem besonders enge oder herzliche Beziehungen.

Auf meine Frage, ob er darüber traurig sei, dass er nicht habe studieren können, antwortet er bejahend, er sei schon öfter traurig, dass er nicht habe studieren können, er habe sich aber inzwischen damit abgefunden: „Es ist einfach zu viel Zeit vergangen, ich kann mich heute nicht mehr als Schüler verstehen, ich hab' zu viel um meine Entwicklung kämpfen müssen“".

Beim Sprichwörterdeuten, Unterschiedsfragen, beim Erkennen von Unstimmigkeiten und beim Bilderdeuten sind die Antworten recht konkretistisch oder sehr abschweifend, fantastisch, weit entfernt von dem Wesentlichen, worum es geht. Beim Schneeballbild, ein Junge hat mit dem Schneeball ein Fenster eingeworfen, wechselt er rasch die Ebene, spricht in etwas verblasener Weise von Tragik (dass der Vater den Sohn züchtigt und dass ihm dies doch weh tut und dass es schade sei, dass die Fensterscheibe eingeworfen worden sei). Überhaupt tendiert er zu leerem-pathetischem Gefasel. Bei den übrigen Bildern hält er sich an Einzelheiten auf bzw. fest, kann diese jedoch nicht in einen richtigen sinnvollen Zusammenhang einordnen.

Seine derzeitige Medikation kann der Patient richtig angeben (5-5-10 mg Fluanxol und 14-tägig 10\%-ig 100mg Fluanxol D i.m).

\section{Zusammenfassung}

Es handelt sich um eine chronische paranoide Schizophrenie mit jahrelang bestehenden negativen Symptomen, vom Alter von 9 Jahren bis zum Alter von 30 Jahren. Seit diesem Zeitpunkt ist der Patient chronisch paranoid-halluzinatorisch. U.a. bestand eine 7 lahre lang andauernde produktiv-psychotische Symptomatologie. Der Patient ist nach wie vor psycho- 
tisch, er halluziniert akustisch (imperative Halluzinationen), er gerät dabei in katatone Erregungszustände mit Tobsuchtsanfällen und kataleptischen Haltungen. Dies geht mit starken Ängsten einher. Der Patient fühlt sich in Zuständen, in denen er erregt und ängstlich ist, von großen starken Männern bedroht, z.B. durch Betreuer und Mitbewohner. Wenn er unter dem Einfluss von Stimmen ängstlich und erregt wird, gerät er in kataleptische Haltungen, er verrenkt sich dann und nimmt bizarre Haltungen ein, in denen er verharrt, wobei er vor sich hin murmelt. Vorwiegend hört er die Stimme seines ehemaligen Gymnasialdirektors, die ihm sage, dass er von bestimmten Personen, großen starken Männern, bedroht werde.

Deutliche affektive Verflachung, emotionales Zurückgezogensein, starke Antriebsschwäche. Seine Antworten sind teilweise verschroben, alogisch, asymbolisch, abschweifend, tangential. Der Verlaufstyp der Psychose ist kontinuierlich mit prominenten negativen und produktiven (paranoid-halluzinatorischen) Symptomen und Denkstörungen (ICD-10: F 20.0, DSM-IV 295.30). Ab dem Alter von 37 lahren ist die Symptomatik vorwiegend kataton mit stuporösen und kataleptischen Zuständen und imperativen akustischen Halluzinationen (F 20.2, 295.20). Postpsychotisches Residuum (DAS-M-3: 4).

\subsubsection{3a}

Nachbeobachtungszeit: 40 Jahre

Familienanamnese: Vetter der Mutter mit 15 Jahren Suizid; Kind einer Cousine der Mutter mehrfache Suizidversuche

Milieu

Vater Fabrikbesitzer, tatkräftig, energisch, als Kind gehemmt, Mutter aus alter Patrizierfamilie, asthenisch, kontaktschwach

Eigenanamnese: zweites von vier Kindern, spätes Sprechenlernen

\section{Prämorbid}

Still, gehemmt, scheu, verträumt, gutmütig, Einzelgänger. In der Schule trotz guter Leistungen überängstlich, ehrgeizig.

Erkrankungsalter: 10 Jahre

Beginntyp: schleichend

Symptomatologie

Der Junge, der schon immer ein stilles, scheues, verträumtes Kind war und in der Schule gute bis sehr gute Leistungen bot, zog sich im Alter von 10 Jahren völlig von den Mitmenschen zurück, saß untätig herum, hatte an nichts mehr Interesse, sprach kaum noch, nahm eine merkwürdige, gebeugte Haltung an, sah keinen mehr an, schaute dauernd auf seine Finger und knabberte an den Nägeln. In der Schule arbeitete er nicht mehr mit, zu Hause war er zeitweise unmotiviert frech und aggressiv. Er entwickelte eine starke WC-Angst (s.a. Kap. 17!) und ging schließlich überhaupt nicht mehr allein auf die Toilette, verließ das Zimmer, sobald Besuch kam, und frühstückte nicht mehr mit der Familie, wenn die langjährige Hausschneiderin dabei war. Seine Haltung war schließlich völlig gebeugt und verkrampft, die Bewegungen steif und eckig, "wie aufgezogen“ und seine Mimik ausdrucksarm und leer. Er wirkte völlig unbeteiligt und leer und zeigte vor allem Unbekannten Angst und Misstrauen. 
Abends, wenn er alleine war, wurde er aktiv, rumorte in seinem Bett herum, redete laut oder leise vor sich hin und schlief erst spät ein. Gelegentlich spielte er „Hund“, indem er den Haushund nachahmte und nässte dann auch wie ein Hund auf den Fußboden. Oder er spielte „Orchester“ und sprach dabei von „Hermann“ (das Hermann-Hagestedt-Rundfunkorchester damit meinend).

Nach 4-wöchigem stationären Aufenthalt begann er mit dem Pflegepersonal hinter der Tür zu sprechen, verlangte gierig nach Süßigkeiten, die er zunächst nur verzehrte, wenn er allein war. Allmählich schloss er sich mehr und mehr an die Hausmutter an, jedoch hatte er nach wie vor keinen Kontakt zu Kindern. Seine Haltung wurde allmählich aufrechter und gelockerter, mit Erwachsenen sprach er direkter und sah sie dabei an. Er begann zu malen, meistens Indianerszenen, baute im Sandkasten, spielte mit der Eisenbahn, schrieb teils konfuse, teils aber auch geordnete Briefe und verfertigte u.a. einen anschaulichen schriftlichen Bericht über einen Zoobesuch. Er machte sogar Schulaufgaben und beteiligte sich am Gruppenleben. Insgesamt war er deutlich antriebsreicher, kontaktfreudiger, interessierter und aufgeschlossener, auch Fremden gegenüber.

Therapie: 12 Elektroschocks, 35 Insulinkomata (!)

\section{Weiterverlauf}

Im Alter von 12 Jahren trat wieder eine Verschlechterung ein, der Junge war von starken Sexualängsten geplagt, er onanierte viel und nässte tags und nachts ein. Er wurde sehr unruhig, vor allem nachts, redete viel unmotiviertes und zusammenhangsloses Zeug, lachte öfters schrill auf ohne ersichtlichen Grund, belästigte das weibliche Pflegepersonal mitunter auch sexuell und wurde recht aggressiv. Im Übrigen zog er sich von den Mitpatienten wieder zurück, deren Berührung er ängstlich vermied. Er spielte nicht mehr und wirkte misstrauisch und verängstigt. In der Folgezeit wechselten katatone Erregungszustände sowie Stuporzustände mit kataleptischen Haltungen, Stereotypien, Negativismus und Mutismus mit Zeiten $a b$, in denen der Junge relativ fügsam und angepasst war und sich kontaktbereiter zeigte. Dann verfertigte er u.a. Zeichnungen (meistens Nussknacker darstellend) und sprach wieder teilweise ganze und sinnvolle Sätze, teilweise jedoch auch unverständliches Zeug (,reden Sie nicht mit den Leuten. Die sind alle schlecht, auch zu den Kindern. Also reden Sie nur nicht. Die Frau singt mit den Kindern und wenn sie singt, dann kommt mir gleich das Schieten"). Eine stetige Besserung war jedoch nicht zu verzeichnen, schließlich wurde der Junge immer teilnahmsloser, affektiv lahm, er war sexuell stark enthemmt, völlig autistisch und zeigte keinerlei Initiative mehr, auch sprach er kein Wort mehr. Stundenlang führte er irgendwelche stereotypen Körperbewegungen aus, sich nicht vom Fleck rührend.

Ab dem 13.-14. Lebensjahr wird das psychotische Bild einförmig, ja eintönig, die Prozessaktivität nimmt ab, der Patient bietet eine als „Dementia praecox“ $b z w$. „Dementia praecocissima" imponierende Wesensänderung. Anfänglich ist zwar noch eine Arbeitstherapie (in der Klammerwerkstatt) möglich, und der Junge antwortet auch noch vereinzelt auf Fragen. Seit dem 19. Lebensjahr spricht der Patient jedoch gar nichts mehr, und seit dem 21. Lebensjahr ist eine Arbeitstherapie überhaupt nicht mehr möglich. Der Patient ist völlig autistisch, antriebslos, mutistisch, unordentlich und unsauber (Einkoten, Einnässen) geworden. Zeitweise muss er sogar zum Essen angehalten werden.

\section{Nachuntersuchung 40 Jahre nach Krankheitsbeginn, Alter des Pat. 50 Jahre}

In den letzten 40 lahren ist das psychopathologische Bild erstaunlich gleich geblieben, es gleicht demjenigen, das der Pat. zu Beginn der Psychose im Alter von 10 Jahren geboten 
hat: Rückzug, Untätigkeit, Interesselosigkeit, gebeugte Körperhaltung, Körperstereotypien, stereotypes Berühren der Fingernägel und Beschauen seiner Handinnenflächen, nur noch leises Flüstern, das kaum verständlich ist. Es bestehen aber eindeutig akustische Halluzinationen, Hören von Stimmen, die ihn ängstigen und offensichtlich bedrohen. Zum Teil haben die Stimmen imperativen Charakter.

\section{Therapie}

In den letzten Jahren Neuroleptika (3mg Haloperidol, 1 mg Tavor, 90 mg Melleril täglich).

Bei der Nachuntersuchung wirkte der Patient ratlos und verträumt. Er fiel durch sein sehr fein geschnittenes Gesicht auf, er stand in gebückter Haltung vor mir, sein Gesicht berührte fast das meine, er flüsterte monoton vor sich hin. Auch seine Hände waren recht differenziert, fein, schmal. Er schaute mich immer wieder an und hatte es gern, wenn man ihn streichelte. Sein Gesichtsausdruck war ganz ähnlich wie derjenige im Alter von 10 Jahren! Auch zeigte er dieselben Symptome: Bestreichen der Fingerspitzen, Anschauen der Fingerspitzen und der Handinnenflächen.

Fragen und Bemerkungen meinerseits wurden im gleichen Tonfall wiederholt (verbale Iterationen $u$. Stereotypien). Dabei wirkte er insgesamt freundlich, fast heiter, er reagierte aber deutlich besorgt, traurig und betroffen, als ich inn fragte, ob er Angst habe. Er schaukelte stereotyp mit dem Körper und äußerte, er dürfe nicht über seine Angst reden! Immer wieder äußerte er den Wunsch, mit mir spazieren gehen zu wollen, schaute mich dabei beschwörend an.

Der Patient berichtete, dass er Stimmen höre, die sagen „Spielen“. Es gäbe aber auch Stimmen, die ihn „beschimpfen“, oder sie sagten "quälen“, „mach” dich nach Hause“. Der Pat. zeigte ein typisches autistisches Symptom: Augenbohren.

Die Frage nach seinem Alter beantwortete er mit „5 Jahre“. Auf die Frage, was er gerne mache, sagte er "Spielen“. (Was?) Antwort: „Dreißig, dreißig, dreißig Grad“ (word chaining s. Kap. 5.2.3). Bei weiteren Fragen wiederholte er jeweils das letzte Wort (Echolalie). Zwischendurch war der Patient "wie in sich versunken", beschäftigte sich mit den Fingerspitzen, stand immer wieder auf, setzte sich hin, beschaute stereotyp seine Handinnenflächen und seine Finger, die er verbog, schaute sich ratlos um. Es hatte den Anschein, als ob er mit inneren Erlebnissen oder mit Stimmenhören beschäftigt sei.

Fremdanamnestisch ist durch die Stationsärztin und den Stationspfleger zu erfahren, dass der Patient völlig autistisch sei, er liege vorwiegend im Bett mit der Decke über dem Kopf. Immer wieder äußere er Angst und sage „ich will nach Hause“. Immer wieder sei er Opfer von verbalen und tätlichen Aggressionen der Mitpatienten. Gerne fasse er anderen Leuten an die Nase oder patsche mit der Hand ins Essen der Mitpatienten, was seine Form der Kontaktaufnahme mit innen sei. Er wimmere viel vor sich hin, spreche unverständlich, hastig-monoton. Er gehe gerne in die Cafeteria und esse Kuchen, auch gehe er gern spazieren, vorwiegend mit einem schizophrenen Mitpatienten. Er finde auch allein wieder auf Station zurück vom Gelände, im Klinikgelände sei er einigermaßen orientiert.

Der Patient sei eher apathisch, habe Phasen, wo er hektisch hin- und herlaufe und vor sich hin murmele, rasch und unverständlich. Dabei bestehe der Eindruck, dass er dann akustisch halluziniere. Er lese in Kinderbüchern, betrachte die Bilder und lese einzelne Wörter. Zur Hygiene müsse er angehalten werden, auch zur Körperpflege.

Das Symptombild bestehe nunmehr seit 30 lahren und habe sich nicht verändert. Der Patient sei gut zu haben, lediglich durch sein autistisches Verhalten komme es zu Konflikten, 
weil er dadurch die Aggressionen der anderen Mitpatienten auf sich ziehe. Er könne sich dagegen jedoch nicht wehren. Zeitweise ziehe er sich ins Bett zurück, ziehe sich ganz nackt aus und uriniere ins Bett, keinerlei sexuelle Aktivitäten, keine Onanie. Der Patient ziehe sich alleine an. Immer noch, wie vor 40 Jahren, als er 10 Jahre alt war, drehe er an seiner Kleidung die Knöpfe ab.

Am Schluss möchte der Patient wieder mit mir spazieren gehen.

\section{Gesamtdiagnose}

Katatone Schizophrenie (F 20.20, 295.20), schweres Residuum (DAS-M-3: 5)

\section{Verlaufstyp}

Kontinuierlich. Ohne wesentliche Progredienz mit prominenten negativen, jedoch auch produktiven Symptomen, Haltungs- und Bewegungsstereotypien, Katalepsie.

\subsubsection{3b}

Nachbeobachtungszeit: 32 Jahre

Familienanamnese: unauffällig

Milieu

Der Vater der Patientin, Lehrer von Beruf, fällt in den letzten Kriegstagen des 2. Weltkrieges. Nach Aussagen der Mutter war die Ehe glücklich. Mutter überbesorgt, sieht bevorzugt das Negative, rechthaberisch, schwierig im Umgang.

\section{Eigenanamnese}

Schwangerschaft der Mutter war "sehr schlecht", sie hatte "dauernd erbrochen“. Schwere Geburt. Die Mutter hat das Kind bis zum 10. Monat gestillt, das Kind hat häufig erbrochen.

Prämorbid: Ängstlich, gute Schülerin (Klassenbeste), spielt Klavier.

Erkrankungsalter: 10 Jahre

Beginntyp: schleichend

\section{Symptomatologie}

Bis zum 4. Schuljahr gehörte das Mädchen zu den besten Schülerinnen, wurde dann jedoch zerfahren, unaufmerksam, ließ sich leicht ablenken. Die Schrift wurde unleserlich, das Mädchen entwickelte starke Hemmungen, wurde ängstlich, verkrampfte sich, war andererseits gutmütig, ließ sich von anderen ausnutzen. Das Mädchen wurde zunehmend unselbstständig, phlegmatisch, ließ in den Schulleistungen ganz erheblich nach, hatte an nichts mehr Interesse, war unsauber, zunehmend gehemmt, ängstlich und scheu und zog sich von allen Kindern zurück. Sein Verhalten wurde läppisch, linkisch-ungeschickt. Es fing an zu regredieren, spielte mit Puppen und kleineren Kindern, von denen es sich ausnutzen ließ.

Im Verlauf eines Jahres wurde das Mädchen antriebs- und interesselos, affektiv leer, ohne innere Bindung an die Mutter, die sie einmal wahnhaft schreckhaft verkannte: „da bist du Ungeheuer ja schon wieder".

Im Alter von 12 Jahren stationäre Behandlung. Das Mädchen war abweisend, teilweise läppisch, antriebsarm, kontakteingeschränkt, immer wieder unmotiviertes Lachen. Es äu- 
Berte, es habe noch nie Mitleid gehabt, und gab an, es habe zu Hause aus der elektrischen Leitung „eine Beeinflussung gemerkt", es seien „überall Strahlen herausgekommen“, die es „an Kopf, Händen, Füßen, Herz, Brust und überhaupt überall hin getroffen“ hätten. Danach lief das Mädchen voller Angst aus dem Zimmer und hatte „richtige Strahlen im Dunkeln gesehen“. Das sei öfters vorgekommen, habe ihr aber "schließlich nichts mehr ausgemacht“.

Therapie: 12 Elektroschocks

\section{Weiterentwicklung}

In der Folgezeit Verschärfung der Symptomatik: Zunehmende Interesselosigkeit, Antriebsmangel, Selbstunsicherheit und Beeinflussbarkeit durch andere. Das nunmehr 12-jährige Mädchen entwickelte Zwangshandlungen (Waschzwang, Ordnungszwang). Es musste sich ununterbrochen die Hände waschen oder Bücher, Bilder und Gebrauchsgegenstände immer wieder von neuem zurechtrücken, aufrichten und säubern. Sein Verhalten war sehr wechselhaft, einige Tage lang verhielt es sich still, zurückgezogen, völlig in sich gekehrt, es ging steif in eigenartiger Körperhaltung mit verrenkten Armen und verdrehtem Körper "wie eine Puppe“ herum, an anderen Tagen war es ausgelassen, überschäumend, läppisch, heiter, albern, ständig in Bewegung und fremden Personen gegenüber distanzlos. Die Patientin war nicht zum Sprechen zu bewegen, wirkte affektiv inadäquat, läppisch, zeitweise stumpf, gleichgültig, ohne Anteilnahme.

Im Alter von 13 Jahren Insulinschockbehandlung, ohne Erfolg. Die Patientin halluzinierte optisch, sie sah u.a. einen Vogel im Zimmer und sah Würmer an der Nase der Mutter entlang kriechen. Stetiger Wechsel von katatonen Erregungs- und Stuporzuständen. Sie äußerte Angst, sterben zu müssen. Weitere Symptome: Echolalie, Phonographismus.

Im Alter von 15 Jahren kataton-stuporöse Zustände, paranoide Wahnideen, akustische und optische Halluzinationen. Das Mädchen ist negativistisch, verschlossen, kontakt- und antriebsarm, musste zeitweise gefüttert werden. Nach wie vor Echolalie.

Im Alter von 16 Jahren kurzzeitige Besserung, die Patientin spricht mehr, hilft beim Abtrocknen und schreibt kurze Briefe an die Mutter, dann jedoch wieder Verschlechterung, die Patientin „verstumpft langsam immer mehr", beteiligt sich nicht mehr an den alltäglichen Vorgängen, beobachtet sie aber genau. Zwischendurch zerstört sie Sachen und lacht dabei, steht dann wieder stumpf in der Ecke herum. Plötzlich geht sie mit einem Besenstiel auf eine Schwester los und läuft plötzlich wieder weg. Immer wieder abrupte, sinnlose Handlungen, Erregungszustände, in denen sie schreit, schlägt, tritt, einnässt, durcheinander lacht und weint.

Im Alter von 17 Jahren stationäre Aufnahme in einem hessischen Landeskrankenhaus, wo sie bis zum Tode verbleibt. Immer wieder ist die Patientin kataton oder stuporös, liegt dann nur noch im Bett, muss gefüttert werden.

Die Folgejahre sind durch katatone Erregungszustände sowie stuporöses Verhalten im Wechsel gekennzeichnet. In erregten Phasen läuft sie laut schreiend herum, ist hoch aggressiv, schlägt Mitpatienten und läuft ziellos im Saal herum, wirft alles um. Sie spricht und singt dann viel und ist sehr unruhig. Zeitweise beschmiert sich die Patientin und das Bett mit Kot. Dabei scheint sie trotz immer weiter fortschreitender affektiver Abstumpfung unter ihrem Zustand zu leiden. So rief sie im Alter von 19 lahren einmal aus: „Ach Schwester, ich bin ja so arm dran, ich bin so furchtbar krank, helfen Sie mir doch". Gelegentlich sagte sie ganze Sätze wie z.B. im Alter von 21 Jahren: „Mir geht es ganz gut, wenn der Kopf gewaschen ist“. Und im 
Alter von 22 Jahren: „Macht mich doch tot“. Im Alter von 23 Jahren schrie sie in einem katatonen Erregungszustand: „Feuer, Blut, Herrgott im Himmel, hilf mir, ich halte es nicht mehr aus, verdammt noch einmal lasst mich los, nein, ich kann und will nicht mehr". Seitdem sprach die Patientin kaum noch, lediglich stoßweise einzelne Wörter ohne inneren Zusammenhang. Immer häufiger kam es zu katatonen Erregungszuständen mit gellendem Schreien, Singen, Toben, Schlagen, Zerstörungswut, abwechselnd mit stuporösen, mutistisch-negativistischen Verhaltensweisen. Seit dem Alter von 27 lahren sprach die Patientin überhaupt nicht mehr, stand unter dem Einfluss von optischen und akustischen Halluzinationen.

\section{Nachuntersuchung}

Im Alter von 29 lahren erfolgte die erste Nachuntersuchung. Die Patientin kam in läppischer Weise ins Zimmer getänzelt, den Kopf zur Seite geneigt und verdreht, sie war negativistischambitendent, sprach nicht, ein Kontakt mit ihr war nicht herstellbar. Von der Stationsschwester war zu erfahren, dass sie wenige Tage zuvor zusammen mit der Mutter Schubert-Lieder mit Text gesungen habe!!

In den Folgejahren vor allem prämenstruell dranghafte Erregungszustände, die Aggressionen sind jedoch nicht mehr so gefährlich wie früher. Vor allem in Erregungszuständen spricht sie auch einige Sätze, ansonsten dauernd mutistisch.

Im Alter von 33 Jahren Suizidversuch durch Strangulation mit Gummiringen.

Im Alter von 42 Jahren Tod im Rahmen eines katatonen Erregungszustandes. Trotz der Fixierung fiel die Patientin aus dem Bett, und es kam zu einer Strangulation durch Druck auf die Halsschlagader mit reflektorischem Herzstillstand.

\section{Zusammenfassung u. Beurteilung}

Schleichend beginnende, chronisch verlaufende Psychose mit Beginn im Alter von 10 Jahren. Knickhaft einsetzende Wesensänderung mit vorherrschenden unproduktiven, negativen Symptomen (Rückzug, affektive Abstumpfung, Interesseverlust), zunehmend unsauber, gehemmt, scheu, ängstlich, aber auch läppisch, erhebliches Nachlassen der Schulleistungen, regressives Verhalten, (Spiel mit Puppen und kleinen Kindern). Im Alter von 11/12 Jahren produktive Symptome wie haptische und optische Halluzinationen, Beeinflussungserlebnisse, Wortneubildungen. Das Krankheitsbild geht über in eine chronische Halluzinose mit kataton-stuporösen Erregungszuständen und vorwiegend optischen und akustischen Halluzinationen (F 20.2). In den letzten 20 Jahren ist das Krankheitsbild gleichbleibend durch schwerste katatone und stuporöse Zustände mit Negativismus, Mutismus und kataleptischen Verkrampfungen gekennzeichnet. Ausbildung eines schweren postpsychotischen Residuums (F20.5, DAS-M-3: 5). 